\title{
Disentangling effects of policy reform and environ- mental changes in the Norwegian coastal fishery for $\operatorname{cod}^{\ddagger}$
}

\author{
Florian Diekert ${ }^{\S}$ and Tore Schweder $₫$
}

December 2016

\begin{abstract}
We construct a detailed bio-economic model of the Norwegian coastal fishery for cod. This fishery has been open-access up to the policy change during the "cod-crisis" of 1989/90. To answer to what extent the subsequent increase in biomass and profits was due to improved management, we isolate the effect of environmental variability. Projecting stock and harvest forward in the counterfactual scenario of no intervention, we show that the policy had a small positive impact on biomass, but a pronounced positive effect on profits. The main drivers of profit gains are increases in productivity and savings in fuel- and labor costs.

(100 words)
\end{abstract}

Key words: Open access, Property rights, Quasi-experiment, Counterfactual control, Bio-economic modeling, Productivity, North-East Arctic cod

JEL codes: C43, D23, Q22, Q28

\footnotetext{
${ }^{\ddagger}$ We would like to thank Kristen Lund for invaluable input and effort. Furthermore, we would like to thank Chris Anderson, Claire Armstrong, Frank Asche, Chris Costello, Arne Eide, Linda Nøstbakken, Peter Gullestad, Andries Richter, Jim Wilen, and seminar participants in Tromsø, Kiel, Oslo, Seattle, Davis, and at the 20th EAERE conference in Toulouse for fruitful discussions and comments. Finally, our paper has greatly benefited from the constructive comments of four anonymous reviewers and the editor, Daniel Bromley. Whitney Lyle assisted with the editing.

${ }^{\S}$ Corresponding author. Department of Economics, University of Heidelberg, Bergheimerstraße 20, D-69115 Heidelberg, Germany and CEES, Dept. of Biosciences, University of Oslo, P.O.Box 1066 Blindern N-0316 Oslo, Norway. Tel: +47-93819432. E-mail: f.k.diekert@ibv.uio.no During this research, F Diekert was funded by NorMER, a Nordic Centre of Excellence for Research on Marine Ecosystems and Resources under Climate Change.

"Department of Economics, University of Oslo, P.O.Box 1095 Blindern N-0317 Oslo, Norway. Tel: +4722844303. E-mail: tore.schweder@econ.uio.no.
} 


\section{Introduction}

The North-East-Arctic cod (NEA cod, gadus morhua) fishery in the Barents Sea is currently (2016) the most valuable whitefish fishery in the world. Dried cod from Lofoten has been a highly priced export commodity since the Viking Ages. Today, Russia and Norway agree on the annual total allowable catch (TAC) quota and its distribution. While the Russian and European fleets (obtaining roughly $50-60 \%$ of the total TAC) predominantly consist of trawlers, this is not the case for the Norwegian fleet. Rather, the bulk are smaller boats with passive gear that exploit the cod's impressive spawning migration to the coastal areas, especially around Lofoten. Access to this coastal fishery was basically open and the international TAC was not enforced on coastal vessels. At that time the cod stock had reached a record low and the Norwegian authorities pulled the emergency brake: The fishery was stopped in the peak of the season on April 18, 1989. From then on, the authorities have severely restricted fishing by allocating individual quotas and enforcing the TAC more consistently. Subsequently, the cod stock has recovered and profits have gone up. In a nutshell, we ask: were these increases in biomass and profits due to good luck or good management?

Individual quota systems in various forms have now been used for more than thirty years, and their use has increased in scope and scale in the recent decade. Simultaneously, there has been a lively debate around this type of fisheries management; in particular when individual quotas are tradable (ITQs), see e.g. Bromley (2009) and the subsequent commentaries. Many studies have pointed to the positive economic effects of ITQ management (see for example Grafton et al., 2000; Fox et al., 2003; Dupont et al., 2005; Arnason, 2005; Schnier and Felthoven, 2013; Reimer et al., 2014), whereas ecological effects appear to be more mixed (Branch, 2009; Chu, 2009).

Generally, case studies that analyze time series in an attempt to test whether privatization or regulation of common property tends to improve profits face the fundamental problem of correctly identifying the causal effect of policy change: There are neither controlled nor natural experiments for large fisheries. First of all, identifying a treatment effect by randomization is infeasible because of spillover effects. Second, the specific natural and social context of a given fishery makes it virtually impossible to find an adequate control among the set of other fisheries. Lastly, technological developments and, in particular, environmental changes obstruct even the comparison of economic units before and after the regulatory change. 
It is this last aspect that we address in this paper: Fish stocks, and consequently profits, might have risen due to the policy change, but also due to more favorable environmental conditions. Therefore, we build an age-structured bio-economic model to simulate the counterfactual development of the fish stock and economic outcomes, assuming no regulatory change, i.e. that the relationship between stock and harvest did not change. The idea is to utilize the estimated recruitment to the actual population after the intervention, since recruitment is the main source of environmentally induced fluctuations. We assume that the counterfactual recruitment in a year would have been the observed factual recruitment, adjusted by the stock-recruitment curve according to the counterfactual spawning stock. The counterfactual stock is then projected forward, subject to observed natural mortality and counterfactual fishing mortality.

Methodologically, our approach is related to the "synthetic control" analysis that has been pioneered by Abadie and Gardeazabal (2003) and applied to non-renewable natural resources by Mideksa (2013) and to fisheries by Scheld et al. (2012). Here, we construct the counterfactual control not by propensity matching, but by simulating a bio-economic model. ${ }^{1}$ The first objective of our study is to analyze the effect of the 1989/1990 policy change on cod biomass. We present our results in section 5.1. The second objective is to analyze the effect on profits. We do so by taking a structural model of a profit function to an extended dataset of boat-owner combinations in the Norwegian coastal cod fishery. After demonstrating that introducing individual quotas has indeed had a positive and significant effect on profits (section 5.2), we investigate how abolishing the open-access regime has lead to increased profits (section 6.2).

The 1989/1990 policy change has been referred to as the "closing [of] the commons" (Hersoug, 2005). At this point, it is important to emphasize that it is the fact that overall harvest is being constrained (and not per se the introduction of individual quotas as way of allocating the TAC) that has an effect on the stock development. However, the issuing of individual quotas was an integral part of a general policy change that allowed the authorities to enforce the TAC also for coastal vessels. Controlling the harvest of coastal vessels is an important condition for the increase in cod biomass, as these vessels primarily target the cod's spawning stock and thus directly affect the stock's renewability. It is the lower TAC and its stricter enforcement that we pick up in the first part of our analysis and it is the combined 
effect of stricter total quotas and more secure harvesting rights that we analyze in the second part of our study.

The two papers most closely related to our study are Kjesbu et al. (2014) and GómezLobo et al. (2011). Kjesbu et al. (2014) analyze a later management change, namely the introduction of a "harvest-control rule" (HCR). They give an excellent introduction to the natural environment and the current status of the NEA cod and argue that the reduction of fishing mortality was - in part - responsible for the high stock values in recent years. To answer how the cod stock would have evolved were it not for the HCR, or were the HCR introduced earlier, they simulate a biological model. In contrast to Kjesbu et al. (2014), we predict counterfactual recruitment by using counterfactual spawning stock as input in the estimated recruitment relationship, and we take into account that the aggregate harvest rate changes with the level of biomass. Moreover, our emphasis is on the economic dynamics. Similar to our approach, Gómez-Lobo et al. (2011) use the residuals from an estimated model to assess the effect of the Chilean ITQ regime by way of simulating a scenario with and without ITQs. Our study differs from Gómez-Lobo et al. (2011) in that it 1) takes into account that the policy change has an effect on the stock development and 2) compares the counterfactual biomass and profits to the historically observed values instead of comparing a with-ITQ and a without-ITQ simulation.

To the best of our knowledge, our study is the first to combine the assessment of an introduction of individual quotas with an explicit simulation of the counterfactual resource base, thereby disentangling the effects of policy reform and environmental changes. That said, we are well aware of the gulf between the power of a randomized controlled experiment and the evidence that our study might bring. Nevertheless, we take a step towards better understanding the effect of changing the fishery rights regime in an important fishery. Given the central role of institutions for economic performance, we believe that the case-study of the Norwegian coastal fishery is of substantial general interest.

\section{Background}

At first sight, the development of the NEA cod stock could serve as a textbook example of open-access and fisheries management. Biomass has declined from more than 4 million tons after WWII to less than one million ton in the 1980s. At the same time, the stock's 
age structure has been severely truncated, making the stock more susceptible to climatic variations (Rouyer et al., 2011). After the introduction of individual quotas in 1989/90, the trend has turned, and aggregate biomass has reached values above 3 million tons once more (Figure 1).

\section{[Insert Figure 1 here]}

Two boat groups are distinguished in the Norwegian cod fishery: Trawlers and vessels with passive gear (the so-called conventional fleet). The latter group is the backbone of the Norwegian fishing fleet, landing around $70 \%$ of the cod harvest. Trawlers have always been subjected to a licensing scheme, while access for conventional boats has traditionally been open. Since 1977, the Joint Russian-Norwegian Fisheries Commission agrees upon a Total Allowable Catch (TAC) quota, with about 10-15\% allocated to third countries and the remainder is shared equally between the two nations. ${ }^{2}$ However, the quota was de facto not enforced for conventional vessels (Christensen and Hallenstvedt, 2005). ${ }^{3}$ This situation changed radically when the resource stock was in such a dire state that the Norwegian authorities closed the fishery on April 18, 1989. After this shock, the unanimous slogan was "Never again April 18th!" (Hersoug, 2005). In the autumn of the same year, the authorities issued individual vessel quotas in order to achieve a fair distribution of fishing opportunities. The aim was to avoid an Olympic race for the low TAC that was set for $1990 .{ }^{4}$ Although the vessel quotas were by no means popular among the fishers at that time, and all the major parties saw them as a "temporary response to the resource crisis" (Hersoug et al., 2000, p.325), they persist. We argue that the policy change has created a privileged group of fishers that, vested with individual harvesting rights, could benefit from an increasing cod stock as well as from efficiency enhancing adjustments of inputs and outputs.

The fact that the closure of the coastal cod fishery occurred in 1989 is a combination of two factors: First, the cod stock was strongly depleted as a result of a history of overfishing and TACs that were too generous (in almost all years the quotas exceeded the already overly optimistic scientific advice, see Figure A-3 in the Appendix). Second, the fish were particularly easy to catch in 1989 (both because the weather was good and because the spawning stock at Lofoten congregated in shallow waters). The closure was effectuated by dividing the coastal vessels into two groups: A "Group I" that obtained individual quotas, and a "Group II" that continued to fish under a common maximal quota. Access to Group I was restricted while 
access to Group II continued to be open. In line with the political tradition of favoring those fishers with fishing as their sole occupation, access to Group I was based on a minimum catch requirement of the boat (differentiated by vessel length) in one of the years 1987, 1988 or 1989. ${ }^{5}$ The vessels in Group II received about $10-20 \%$ of the total quota that was allocated to the coastal vessels, but in many years, the maximal quota for this group was not filled. Furthermore, there have been several rounds of "promotions" from Group II to Group I, that - together with other regulatory efforts - aimed at increasing flexibility and reducing state intervention without giving up the political aim of maintaining a diverse settlement pattern in Northern Norway. ${ }^{6}$ A delicate act of balance!

A clear manifestation of the aim of the fishery policy to maintain a diverse settlement pattern is the difficulty to transfer vessels and quotas. Initially, boats were not allowed to be sold across municipality borders. This constraint met fierce opposition from the Association of Norwegian Fishermen and was soon changed to a prohibition of vessel trade across county borders. In practice, this limitation was sometimes circumvented by "setting up a post box in the right municipality" (Hersoug, 2005, p.119). Individual quotas are given on the basis of vessel length and were not meant to be transferable at all. Nevertheless, quota trade occurred in practice, at least to some extent, as boats have been sold with a quota and then bought back without the quota $\left(\right.$ Holm and Nielsen, 2007). ${ }^{7}$

At this point, we should highlight that the "cod fishery" is in fact a multi-species fishery: Several species are caught as by-catch when targeting cod, but vessels also target different species for different parts of the year, mainly exploiting variations in the availability of fish. In particular, saithe and haddock are important species in terms of quantity and value. The TAC for haddock is decided bilaterally between Russia and Norway and the saithe TAC is set unilaterally by Norway. Individual quotas for haddock and saithe were only issued from 2003 onward. That said, cod is clearly the main part of the fisheries' catch and the focus of the regulations. The harvest of cod follows a clear seasonal pattern, and the bulk of the annual catch comes from targeting the massive spawning migration (see Figure A-1 in the Appendix). 


\section{Materials}

The biological data and the numbers for aggregate annual landings are taken from the 2012 . ICES report. We point out that when we talk about "observed" stock size, we refer to biomass values that are derived from virtual-population analysis, a model-based technique that back-calculates the stock numbers from fishery-dependent (landing statistics) and fisheryindependent (research surveys) data. The true error will always remain unknown (as the true size of the fish stock in the ocean is in fact unobservable), but it is clear that the error strongly diminishes through time as more information - in particular on the fish stock's age-structure - becomes available.

The economic data that we use comes from the Norwegian Directorate of Fisheries profitability surveys, forming an unbalanced panel with information on vessel characteristics, economic variables, the harvested amount, and the harvested value. The profitability surveys are sent out by mail at the end of each year to all boat owners of "ordinarily well operated and aptly equipped vessels above $13 \mathrm{~m}$ in length that are used to fish the whole year". The survey's response rate was between $31 \%$ and $34 \%$ in $1985-96$ and $27 \%$ in 1997 . The surveys inform the annual negotiations between the Norwegian authorities and the Norwegian Fishermen's Association about i.a. state subsidies, minimum prices and other regulations. To the extent that the data in these surveys is self-reported and potentially subject to selection bias, the information should be treated with the appropriate amount of caution. However, as the report of an individual boat owner is one of several hundreds, it is unlikely that he or she strategically underreports his or her revenue to induce higher subsidies. In particular, the answers to the survey are not being used for any individually targeted policies or to calculate tax payments. For us, it is important that the survey methodology was not changed with the introduction of individual quotas in $1990 .^{8}$

The total number of fishing vessels in Norway has declined from about 24,000 in 1985 to about 13,600 in 1997. The number of vessels that forms the basis of our sample (around 700) has stayed stable over this period. These boats contribute by far the largest part of Norwegian landings, both in terms of volume and in terms of value. About $80 \%$ of all vessels between $13 \mathrm{~m}$ and $28 \mathrm{~m}$ are operated year-round (see Figure A-2 in the Appendix for further details on the constitution of the stock of Norwegian fishing vessels).

We were able to pool the data from all vessels independent of their classification by the 
directorate, which is important because the harvest composition may vary substantially from year to year. The final selection contains 668 unique vessel-owner combinations over 13 years, giving 1,818 observations between 1985-1997 (on average 140 observations per year). In addition, we were able to obtain information on the boat owners from the vessel registry (through the Directorate of Fisheries) and we could match these datasets to create boat-specific histories of ownership. This allows us to control for vessel- and owner specific attributes and importantly - we can distinguish the fate of those boats that have entered or left the fishery.

We do not have information on the individual quota holdings. Therefore, we went through the archives of regulations published by the Fisheries Directorate and collected the information on the individual quotas that were issued for each length group each year and assigned them accordingly. As there is an activity requirement to catch a certain part of the quota to qualify for staying in Group I, we compared quotas to actual catches to determine whether a given vessel belonged to Group I (vessels regulated by an individual quota) or Group II (vessels managed by a maximum group quota). In this way, we identified 9 vessel-owner combinations belonging to Group II, while the remaining 579 vessel-owner combinations belong to Group I.

Furthermore, we do not have information on the fuel price faced by a given boat in a given year. We have therefore used a time series of real petroleum prices. ${ }^{9}$

Table 1 shows the main variables of the economic dataset (where the capital letter $\mathrm{N}$ refers to the total number of observations and the lowercase $n$ refers to the number of distinct boat-owner units). All prices are given in real Norwegian Kroner $(1$ NOK $\approx 0.12$ USD at the time of writing). They have been deflated using the consumer price index $(1998=100)$ from Statistics Norway. ${ }^{10}$

Table 1: Summary statistics, selected variables

\begin{tabular}{lccccc}
\hline Statistic & $\mathrm{N}(\mathrm{n})$ & Mean & St. Dev. & Min & Max \\
\hline Length (meter) & $1818(668)$ & 17.20 & 3.53 & 13.00 & 27.80 \\
Tonnage (BRT) & $1818(668)$ & 43.40 & 36.88 & 11.00 & 233.60 \\
Boat-age (in years) & $1817(667)$ & 22.03 & 15.91 & 0 & 90 \\
Labor (Man-years) & $1818(668)$ & 4.27 & 1.61 & 1.00 & 12.06 \\
Operating days per year & $1818(668)$ & 278.65 & 44.71 & 62 & 364 \\
Harvest (in metric tons) & $1818(668)$ & 368.54 & 413.76 & 5.18 & 3306.44 \\
Share of cod in harvest & $1818(668)$ & 0.46 & 0.24 & 0.05 & 0.99 \\
Revenue (1000 NOK) & $1818(668)$ & 1970.99 & 1439.69 & 97.08 & 10843.85 \\
Total cost (1000 NOK) & $1818(668)$ & 1834.23 & 1292.16 & 180.08 & 10075.68 \\
Variable cost (1000 NOK) & $1818(668)$ & 1151.04 & 812.71 & 59.41 & 7349.87 \\
\hline
\end{tabular}

Our key measure of economic performance is short-run profit, defined as the total revenue minus variable costs. ${ }^{11}$ In the following, we will use the word profits to mean short-run profits. 
Figure 2 shows a box-plot of profits from 1985 to 1997 (the thick lines within the boxes show the median and the black dots show the mean profit in the respective year). The plot highlights the immense variation: The average value of profits in the dataset is 819 thousand Norwegian Kroner (NOK) with a standard deviation (s.d.) of 660 thousand NOK. The variation between different vessels-owner combinations (s.d. of 654 thousand NOK) is much larger than the variation within a vessel-owner combination (s.d. of 197 thousand NOK).

[Insert Figure 2 here.]

\section{Methods}

\subsection{Counterfactual simulation of cod stock}

We simulate how stock biomass would have developed if the 1990 regulatory change had not taken place by using: 1) a function predicting the aggregate harvest for a given stock biomass, 2) a biological model predicting the size of each cohort the next year, accounting for harvest and natural mortality, and 3) a procedure calculating the number of new fish entering the exploited stock as a function of the reproductive part of the stock, while accounting for the historical environmental conditions.

\section{Harvest}

The function that predicts aggregate harvest for a given stock is given by (1), where $H_{t}$ refers to the harvest during year $t$ and $B_{t}$ refers to the stock biomass at the beginning of year $t$.

$$
H_{t}=\alpha+\beta B_{t}+\varepsilon_{t}
$$

Note that we simply search for the most parsimonious empirical relationship with the highest explanatory power. Our interest is in the equation's ability to forecast, and we therefore see (1) as a reduced form of a model of open-access in the cod fishery. Our key assumption is that the relationship between stock and harvest would have been the same also after 1989, were it not for the policy change. Details on the selection of the functional form, its estimation, and the parameter values are placed in Appendix A.2. Here we note that the straightforward linear specification is able to explain almost $90 \%$ of the variation in the data. 


\section{Stock dynamics}

The aggregate stock biomass at time $t+1$ is the number of fish at age $a$ at time $t+1$ times their average individual weight, summed over all ages: $B_{t+1}=\sum_{a}^{A} w_{a, t+1} N_{a, t+1}$. The firstage-at-recruitment is 3 years for NEA cod, and the oldest age-group $A$ (a so-called "plus group", collecting all individuals of age $A$ and above) is 13 years.

In order to project the stock biomass to the next period for a given stock and harvest in the current period, we first need to convert the aggregate harvest at time $t$ to the harvested biomass of age-class $a$ that is caught at time $t$. To this end, we assume that the selectivity pattern does not change with the regulatory regime. ${ }^{12}$ Denote the observed aggregate fishing mortality by $F_{t}$ (which is given by the ratio of aggregate harvest to aggregate biomass $F_{t}=\frac{H_{t}}{B_{t}}$ ) then the age-specific selectivity can be inferred from $H_{a, t}=s_{a} F_{t} B_{a, t}$. Thus, the counterfactual harvested biomass at age is calculated by:

$$
\hat{H}_{a, t}=s_{a} \hat{F}_{t} \hat{B}_{a, t}
$$

The counterfactual Stock-Numbers-at-age $\hat{N}_{a, t}$ are calculated according to equation (3), which means that we assume that fishing occurs instantaneously in the middle of the year, and natural mortality $M_{a, t}$ occurs evenly throughout the year. The values for natural mortality are taken from the ICES report $\left(2012\right.$, Table $3.17 ; M_{a, t}=0.2$ for most $\left.a, t\right)$. To translate the counterfactual harvested biomass into catch-numbers-at-age, we have to divide the harvest-atage by the average individual weight-at-age $w_{a, t}$, where we assert that the individual weightat-age does not change with the regulatory shift. Although it seems intuitive that growth is slower at high stock levels and for NEA cod, weight-at-age is indeed negatively correlated with abundance, the causal mechanism is uncertain: Evaluating biotic and abiotic determinants of cod growth, Ottersen et al. (2002) find that environmental conditions that are correlated with strong recruitment also displace the new year classes farther east into colder water masses, where prey abundance is low and growing conditions are adverse. As environmental conditions have not changed due to the policy change, we employ the yearly values as they are given in Table 3.7 in ICES (2012). 


$$
\begin{aligned}
\hat{N}_{a+1, t+1} & =\left(N_{a, t} e^{-\frac{M_{a, t}}{2}}-\frac{\hat{H}_{a, t}}{w_{a, t}}\right) e^{-\frac{M_{a, t}}{2}} \\
\hat{N}_{A, t+1} & =\left(N_{A-1, t} e^{-\frac{M_{A-1, t}}{2}}-\frac{\hat{H}_{A-1, t}}{w_{A-1, t}}\right) e^{-\frac{M_{A-1, t}}{2}}+\left(N_{A, t} e^{-\frac{M_{A, t}}{2}}-\frac{\hat{H}_{A, t}}{w_{A, t}}\right) e^{-\frac{M_{A, t}}{2}}
\end{aligned}
$$

\section{Recruitment}

Finally, the number of recruited fish (at age 3) is needed. To this end, we must isolate the influence of the (endogenous) spawning stock biomass from the (exogenous) environmental forces determining recruitment. The link between biomass and recruitment is assumed to follow the Beverton-Holt form (Ohlberger et al., 2014):

$$
N_{3, t}=\frac{e^{a} S S B_{t-3}}{1+e^{b} S S B_{t-3}} \cdot e^{\varepsilon_{t}}
$$

where the parameters $a$ and $b$ are obtained from a non-linear regression of the number of recruits on the spawning stock biomass $(S S B)$. Regression estimates are given in Appendix A.3. Since NEA cod is considered to recruit to the fishery at age 3, the relevant spawning stock biomass is the one three years earlier. ${ }^{13}$ The counterfactual spawning stock biomass will differ from the observed values, and will hence drive a wedge between the counterfactual and the predicted recruitment values. However, we add the observed time-specific residual from the regression to the log of the recruitment values. The residuals are - by assumption - independent of the stock size and capture random environmental fluctuations (climatic or oceanographic conditions, predator and prey abundance etc). ${ }^{14}$

We use a multiplicative lognormal error structure, which can be justified for several reasons. First, from a technical perspective, the explained variable can only take on positive values. This is particularly important for the simulation, where negative recruitment values could occur if an additive model structure were applied. Second, from a statistical perspective, the multiplicative model gives the better fit (see Appendix A.3, where we also show the regression results for the additive model). Third, from a mechanistic perspective, when the total survival from egg to recruit is viewed as the product of the probability of many smaller survival events (Quinn and Deriso, 1999). 
[Insert Figure 3 here.]

Figure 3 illustrates the simulation procedure. The left panel shows the observed scatter of $S S B$ versus abundance at age 3 three years later. The fitted Beverton-Holt function is given by the blue line. The right panel shows one hypothetical simulation step: Suppose the observed $S S B$ at time $t-3$ was at 650 thousand tons. The stock-recruitment function predicts that there would be around 700 million recruits, while - due to environmental conditions - the actual observed recruitment was 1,300 million individuals. If now the counterfactual SSB at time $t-3$ were at 250 thousand tons, the stock-recruitment function would predict around 462 million recruits, but by multiplying the observed residual, we end up with a counterfactual recruitment of 925 million individuals.

The simulation has been implemented in $\mathrm{R} 3.1 .1$ (2014). In order to quantify the uncertainty surrounding our simulations, we run a thousand simulations where we, for each time step, add an error to the harvest and to the residual of the recruitment function. The former is a randomly drawn residual from the harvest regression and the latter is taken from a normal distribution with a standard deviation corresponding to the estimates of the 0-group abundances obtained from the Barents Sea ecosystem survey (Anon., 2011). Uncertainty in growth and mortality is not accounted for because we assume that the policy change had no effect on these processes.

\subsection{Estimation of policy effect on profits}

The second objective of our study is to estimate the effect of introducing individual quotas on profits. In parlance of a "program evaluation" approach, we want to estimate the average treatment effect for our study period: $A T E=\sum_{t=1990: 97}\left[\frac{1}{N} \sum_{i}^{N} Y_{i, t}(1)-Y_{i, t}(0)\right]$, where $Y_{i, t}(1)$ is the outcome variable of interest (profits) for a treated individual at time $t$, and $Y_{i, t}(0)$ denotes the counterfactual outcome were the individual not treated. While $Y_{i, t}(1)$ is observed, $Y_{i, t}(0)$ is unobservable. In order to construct $Y_{i, t}(0)$, we fit a profit function to the data where we control for individual quotas and include dummy variables for the period 1990-1997 to capture adaptations to the new policy regime.

Profits $\pi_{i, t}$, are generated by some unknown process. We describe this process by a linear approximation to the log-transformed profits as a function of output prices, the inputs labor and fuel, and the biomass of the harvested fish stocks (in the actual estimations we retain 
only the cod stock). That is, we presume a simple Cobb-Douglas profit function, which we have chosen because it proved to be sufficiently robust for extrapolating. ${ }^{15}$ While we allow for systematic vessel-owner specific differences, for example due to skipper skill or location of the home port, we assume that all other factors are not systematically related to the observed profits. Formally, counterfactual profits are calculated according to:

$$
\begin{aligned}
& \hat{\pi}_{i, t}=\exp \left(\hat{\alpha}_{i}+\sum_{l} \hat{\beta}_{l} \ln p_{l, i, t}+\hat{\beta}_{L} \ln L_{i, t}+\hat{\beta}_{F} \ln F_{t}+\hat{\beta}_{B} \ln \hat{B}_{t}\right) ; \\
& \quad \text { for } t \in[1990,1997] ;
\end{aligned}
$$

The coefficients $\hat{\alpha}_{i}$ and $\hat{\beta}$ are estimated by regressing:

$$
\begin{aligned}
\ln \pi_{i, t}= & \alpha_{i}+\sum_{l} \beta_{l} \ln p_{l, i, t}+\beta_{L} \ln L_{i, t}+\beta_{F} \ln F_{t} \\
& +D_{t}\left(\sum_{l} \beta_{D l} \ln p_{l, i, t}+\beta_{D L} \ln L_{i, t}+\beta_{D F} \ln F_{t}\right)+\beta_{B} \ln B_{t}+\beta_{Q} \ln Q_{i, t}+\varepsilon_{i, t} ;
\end{aligned}
$$

$$
\text { for } t \in[1985,1997] ; \quad \varepsilon_{i, t} \sim \text { iid. } \mathcal{N}\left(0, \sigma^{2}\right)
$$

Here, $p_{l, i, t}$ is a vector of output prices (where $l=\operatorname{cod}$, haddock, or a composite price index of other species), observed by individual $i$ at time $t . L_{i, t}$ is the amount of labour (assumed to be fixed in the short run). $F_{t}$ is the fuel price and $B_{t}$ is the observed biomass of the cod stock. Note that we use the counterfactual biomass $\hat{B}_{t}$ in the projection (5). The individual fixed-effect $\alpha_{i}$ applies to the level of a boat-owner combination; a Hausman test $\left(\chi^{2}=272.4\right)$ clearly rejected the use of a random-effects model. The dummy variable $D_{t}$ is set to 0 for $t$ in 1985-89 and set to 1 for $t$ in 1990-97. It allows the input- and output-coefficients to be different before and after the intervention. In addition, we control for the quota holding (in tons) $Q_{i, t}$ of individual $i$ at time $t$. The coefficient $\beta_{Q}$ is set to zero in the counterfactual projection (equation 5).

Estimates are obtained by applying ordinary least squares with fixed effects (the "within" option in the "plm" package in R; Croissant and Millo, 2008) directly to the profit function described in equation (6). We thus exploit duality to avoid the endogeneity problem that arises when using labour and capital as proxy for effort (Gordon, 2013). Consequently, the exogeneity of prices and fact that the individual firm adjusts in- and outputs are important 
maintained assumptions. As the products from the demersal fish species are either a small part of the larger world-market for white fish, or go to the specialized market for dried fish where the final price depends much on the idiosyncratic characteristics of the individual fish and the weather during the drying period, this assumption is likely to hold for the output prices. The assumption that the amount of employed labour is fixed in the short run is maybe more problematic, but clearly the decision how many men to employ has to be taken before the fishing trip. Using wages is not an alternative, as labor renumeration is directly linked to harvest due to the share system. Our fixed-effect controls for capital, but we cannot estimate its effect. With respect to fuel, we do not have information on individual prices and were therefore forced to use an annual index that is the same for all units. ${ }^{16}$ The advantage of this is of course that this index is not influenced by individual decisions. Finally, we control for the biomass of the cod stock, but not for other species. We have decided against including the biomass of the haddock or the saithe stock firstly because models that included them had higher AIC values and secondly because the coefficients for the haddock and saithe stock, respectively, were not statistically significant. Note that this leads to an implicit assumption that the biomass of the other targeted species has no systematic effect on profits.

\section{$5 \quad$ Results}

\subsection{Counterfactual simulation of cod stock}

Was the increase of the cod stock due to good luck or due to good management? In order to answer this question, we have projected how stock biomass would have developed if the relationship between stock and harvest after 1990 had been the same as before 1990: The black line with solid points in Figure 4 gives the actual observed stock development, while the blue line with open circles shows the counterfactual cod stock. The dashed lines plot the 95\% simultaneous confidence bands (Schweder and Hjort, 2016). A sample of hundred paths used to generate these confidence bands are in the background.

$$
\text { [Insert Figure } 4 \text { here.] }
$$

The policy has had a positive effect on stock biomass: The observed stock is significantly larger than our counterfactual projection of the stock biomass in the absence of intervention. Nevertheless, it appears that the main part of the post-1990 increase in the stock size was 
independent of the policy change. Three drivers are identified in the literature (see e.g. Godø, 2003, Hjermann et al. 2007): First, a recovered capelin stock (the main prey of cod) in the early 1990s significantly improved the feeding conditions and consequently reduced cannibalism. Second, warmer temperatures generally benefited cod (which lives at its Northernmost boundary in the Barents Sea). Third, oceanographic conditions were favorable in this period as they predominantly transported cod larvæ into nutrient rich waters.

Note that the effect is not as crystal clear as one may have hoped; the observed stock development overlaps with the $95 \%$ simultaneous confidence band in some years (in particular in the beginning, which is expected because of the filtering effect of the fish stock's age structure). A one-sided confidence band at level $94 \%$ is entirely below the observed stock trajectory or just touches it.

\subsection{Estimation of policy effect on profitability}

Did the stricter enforcement of the TACs and the introduction of individual quotas have a significant positive effect on profits? To answer this question, we fitted a profit function to data from 1985-1997, controlling for quotas and including dummy-variables for the post-policy period. We derive counterfactual profits by projecting this function but setting the coefficients of the quotas and post-policy dummies to zero as well as employing the counterfactual cod biomass instead of the observed biomass.

Figure 5 shows that the policy change of 1989/90 led to a significant increase in profits, in particular after three to four years. This pattern conforms exactly to what we would expect from theory: In the first years, the reduction of harvest due to the quota constraint has a negative effects on profits that is only partially canceled by an increasing stock and other beneficial effects of the policy change. In the later years, the net effect is clearly positive as - in addition to learning and other efficiency enhancing adaptations - the stock has grown further and individual quotas have increased accordingly, so that now more can be harvested from a healthier resource stock.

$$
\text { [Insert Figure } 5 \text { here.] }
$$

Table 2 presents the results of the fixed-effects regressions of the profit function. The baseline case when the entire sample is used is given in column (1), whereas column (3) presents 
Table 2: Regression Results for Cobb-Douglas Profit Function

\begin{tabular}{|c|c|c|c|c|}
\hline \multirow{3}{*}{$\begin{array}{l}\text { Independent } \\
\text { variables (on log-scale) }\end{array}$} & \multicolumn{4}{|c|}{ Dependent variable: $\ln \pi$} \\
\hline & \multicolumn{2}{|c|}{ Full sample } & \multicolumn{2}{|c|}{ Restricted sample } \\
\hline & $(1)$ & $(2)$ & (3) & (4) \\
\hline (Intercept) & $\begin{array}{l}2.257^{* * *} \\
(0.715)\end{array}$ & $\begin{array}{l}1.798^{* *} \\
(0.724)\end{array}$ & $\begin{array}{l}3.336^{* * *} \\
(0.896)\end{array}$ & $\begin{array}{l}3.341^{* * *} \\
(0.943)\end{array}$ \\
\hline Cod price & $\begin{array}{l}0.205^{* *} \\
(0.104)\end{array}$ & $\begin{array}{r}0.185^{*} \\
(0.105)\end{array}$ & $\begin{array}{c}0.151 \\
(0.121)\end{array}$ & 0.151 \\
\hline $\begin{array}{l}\text { Dummy } \\
\text { cod price }\end{array}$ & $\begin{array}{l}0.366^{* *} \\
(0.145)\end{array}$ & $\begin{array}{l}0.413^{* * *} \\
(0.146)\end{array}$ & $\begin{array}{l}0.510^{* *} \\
(0.197)\end{array}$ & $\begin{array}{l}0.510^{* *} \\
(0.196)\end{array}$ \\
\hline Haddock price & $\begin{array}{l}0.109 \\
(0.0734)\end{array}$ & $\begin{array}{c}0.134^{*} \\
(0.0740)\end{array}$ & $\begin{array}{c}0.0909 \\
(0.0845)\end{array}$ & $\begin{array}{c}0.0907 \\
(0.0854)\end{array}$ \\
\hline $\begin{array}{l}\text { Dummy } \\
\text { haddock price }\end{array}$ & $\begin{array}{r}-0.190^{*} \\
(0.101)\end{array}$ & $\begin{array}{r}-0.179^{*} \\
(0.100)\end{array}$ & $\begin{array}{c}-0.194 \\
(0.141)\end{array}$ & $\begin{array}{c}-0.194 \\
(0.142)\end{array}$ \\
\hline Other price & $\begin{array}{c}0.0716 \\
(0.0636)\end{array}$ & $\begin{array}{c}0.0809 \\
(0.0640)\end{array}$ & $\begin{array}{c}0.0916 \\
(0.0787)\end{array}$ & $\begin{array}{c}0.0916 \\
(0.0790)\end{array}$ \\
\hline $\begin{array}{l}\text { Dummy } \\
\text { other price }\end{array}$ & $\begin{array}{c}-0.0543 \\
(0.0630)\end{array}$ & $\begin{array}{c}-0.0639 \\
(0.0632)\end{array}$ & $\begin{array}{c}-0.0878 \\
(0.0745)\end{array}$ & $\begin{array}{c}-0.0877 \\
(0.0739)\end{array}$ \\
\hline Labor & $\begin{array}{l}1.046^{* * *} \\
(0.132)\end{array}$ & $\begin{array}{l}1.033^{* * *} \\
(0.132)\end{array}$ & $\begin{array}{l}1.029^{* * *} \\
(0.172)\end{array}$ & $\begin{array}{l}1.029^{* * *} \\
(0.173)\end{array}$ \\
\hline $\begin{array}{l}\text { Dummy } \\
\text { Labor }\end{array}$ & $\begin{array}{l}-0.652^{* * *} \\
(0.103)\end{array}$ & $\begin{array}{l}-0.624^{* * *} \\
(0.106)\end{array}$ & $\begin{array}{l}-0.603^{* * *} \\
(0.113)\end{array}$ & $\begin{array}{c}-0.604^{* * *} \\
(0.120)\end{array}$ \\
\hline Fuel price & $\begin{array}{l}0.260^{* * *} \\
(0.0633)\end{array}$ & $\begin{array}{l}0.324^{* * *} \\
(0.0690)\end{array}$ & $\begin{array}{l}0.118 \\
(0.0806)\end{array}$ & $\begin{array}{l}0.117 \\
(0.0922)\end{array}$ \\
\hline $\begin{array}{l}\text { Dummy } \\
\text { fuel price }\end{array}$ & $\begin{array}{r}-0.192^{* *} \\
(0.0778)\end{array}$ & $\begin{array}{c}-0.206^{* * *} \\
(0.0780)\end{array}$ & $\begin{array}{c}-0.235^{* *} \\
(0.112)\end{array}$ & $\begin{array}{c}-0.235^{* *} \\
(0.111)\end{array}$ \\
\hline Cod biomass & $\begin{array}{r}0.128^{* *} \\
(0.0557)\end{array}$ & $\begin{array}{l}0.152^{* * *} \\
(0.0559)\end{array}$ & $\begin{array}{c}0.0681 \\
(0.0714)\end{array}$ & $\begin{array}{c}0.0679 \\
(0.0732)\end{array}$ \\
\hline Indiv. quota & $\begin{array}{l}0.294^{* * *} \\
(0.0317)\end{array}$ & $\begin{array}{l}0.246^{* * *} \\
(0.0458)\end{array}$ & $\begin{array}{l}0.253^{* * *} \\
(0.0444)\end{array}$ & $\begin{array}{l}0.254^{* * *} \\
(0.0677)\end{array}$ \\
\hline Time trend & & $\begin{array}{c}0.0197 \\
(0.0130) \\
\end{array}$ & & $\begin{array}{c}-0.000165 \\
(0.0176) \\
\end{array}$ \\
\hline $\mathrm{N}(\mathrm{n})$ & $1818(668)$ & $1818(668)$ & $691(123)$ & $578(282)$ \\
\hline$R^{2}$ & 0.62 & 0.62 & 0.63 & 0.63 \\
\hline $\mathrm{AIC}$ & 1208 & 1206 & 476 & 473 \\
\hline
\end{tabular}

Fixed-effect within regression; ${ }^{*} p<0.10,{ }^{* *} p<0.05,{ }^{* * *} p<0.01$

(Standard errors in parentheses, clustered at the level of boat-owner combination) 
the results from the robustness check of using only those vessel-owner combinations that have been observed before and after the change. (Corresponding to Figure 5, we present average observed and counterfactual profits for this restricted sample in Figure A-9 in the Appendix). Columns (2) and (4) show the results when we have added a time trend to the regressions of columns (1) and (3), respectively.

The key observation from Table 2 is the positive and highly significant effect of individual quotas. Indeed, the individually harvested amount of cod has increased strongly and monotonically after 1990 (see Panel A in Figure 7). In line with the comparison between the observed and counterfactual profits, this indicates that the efficiency gains from the policy reform unfolded over time. Although it is beyond the scope of this study to decompose changes along the intensive and extensive margin by an elaborate structural model (as e.g. in Reimer et al., 2014), we investigate how the policy change has lead to increased profits in section 6.2. In short, we argue that participants, having secured rights to harvest, could adapt the allocation of inputs and outputs to minimize cost and maximize profits (in addition to benefiting from an increased cod stock).

\section{Discussion}

In this section, we discuss alternative mechanisms that could have lead to the observed increase in cod stock biomass and how the policy change has increased profits.

\subsection{Alternative mechanisms leading to an increase in the cod stock}

Our simulation of the counterfactual cod stock relies on aggregate data from the ICES reports. The estimated impact of the policy could therefore be unrelated to the introduction of individual quotas in the Norwegian coastal fishery.

First, it could be that it was the Russian (Soviet) harvest that has decreased after the fall of the Iron Curtain. We have collected data on quotas and harvest on a country-by-country basis. The data clearly shows that the Russian harvest did not fall after 1990 — to the contrary, it increased (see Figure A-4 in the Appendix). In fact, after the disintegration of the Soviet Union and the ensuing re-orientation from a "tonnage ideology" to the market and the phasing-out of fuel subsidies, the Russian fleet was much more interested in harvesting 
high-value cod in the nearby Barents Sea (Hønneland, 2006).

Second, it could be that the reduction in harvest was only due to a more conservative setting of the TAC and stricter enforcement. While the agreed quotas were indeed closer to the scientific advice and the degree of overfishing has been reduced, we show that quotas were set in excess of the scientific advice and overfishing was also prevalent after 1989/90. On average, quotas were $27 \%$ larger than the scientific advice before 1990 and $13 \%$ larger than the scientific advice after 1989. Harvest has, on average, exceeded quotas by $10 \%$ before 1990 and by $5 \%$ after 1989 (Figure A-3). However, when quotas and harvest are analyzed in differentiated way on a fleet-by-fleet basis, it becomes clear that it was the overfishing of the Norwegian conventional fleet that was stopped after the 1989/90 policy change (Figure A-4). After 1989, their harvest never exceeded the quota.

Moreover, we have subjected our model to two placebo tests as a falsification strategy. That is, by applying the model to units that have not actually been treated, we learn whether the reported results could be driven by the model's inability to replicate the true data. In other words, if our method of constructing a counterfactual cod stock is correct, we should not see a large deviation between counterfactual and actual stock estimates when assuming that the policy change would have happened in 1980 or 1985. Indeed, no significant difference between the actual stock biomass and the counterfactual projections is discernible in Figure 6 when the treatment is fictitiously applied in 1980 (left panel) and 1985 (right panel).

[Insert Figure 6 here.]

In conclusion, we argue that the policy change in $1989 / 90$ is likely to have had a positive effect on the stock development, but that the fluctuations in the cod stock are primarily driven by environmental factors. ${ }^{17}$ This somewhat ambiguous finding is in line with previous difficulties establishing clear positive ecosystem effects of ITQ management (Branch, 2009, Chu, 2009). It also reflects the recent work of Rouyer et al. (2011), who argue that the qualitative changes of the stock's properties, in particular its age-truncation, has increased the importance of climatic conditions for stock dynamics. Further, also Kjesbu et al. (2014) find, in their words, "synergies between climate and management" when investigating the introduction of the harvest-control-rule in 2007. 


\subsection{How the policy change has increased profits}

We now turn to a discussion of the underlying drivers of the observed profit gains. While there is some evidence of capacity expansion as vessels that newly enter the fishery tend to be larger than the old vessels that leave the fishery (more on this below), there is no sign of technological improvement for the existing vessels (Standal and Aarset, 2002). In columns (2) and (4) of Table CD results, we have accounted for technological change by including a time trend. The coefficient is not significantly different from zero, neither in the full sample, nor in the sample of those boats that are observed both before and after the policy change.

Also, the alternative explanation of higher post-reform output prices that is common in North American fisheries (Grafton et al., 2000; Fox et al., 2003; Dupont et al., 2005) cannot account for the observed increases in profits. As Figure 7 -B shows, we do not see that prices increased after the introduction of individual quotas. The reason is probably that the pre-ITQ regulations in many North American fisheries led to extremely short harvesting seasons, so that there was much to gain from alleviating these adverse market effects. In Norway, the availability of fish has always been determined by the spawning migration and other environmental fluctuations. The harvesting season was never so extremely short that latent potential gains were not present to the same extent. ${ }^{18}$ Furthermore, the absence of a significant coefficient of the dummy for the price index of other species shows that there are no signs of an increased importance of unregulated species as the cod fishery becomes regulated (in contrast to the Norwegian pelagic fleet; see Asche et al. 2007).

Rather, the introduction of individual quotas allowed the firms to avoid a costly "race to fish". Analyzing the elasticities (which - for a Cobb-Douglas profit function - are conveniently given by the regression coefficients), we see that the responsiveness of individual vessel profits to the fuel price has declined significantly after the policy change. Similarly, while a $1 \%$ change in labour use was associated with about a 1.04\% change in profits before 1990, a $1 \%$ change in labour use was associated with only about $0.39 \%$ change in profits after the policy change (see Table 2, column 1). As Abbott et al. (2010), we find little evidence of changes in the share of labor cost to revenue. While the overall amount of labor (measured in man-years) was increasing before 1990, it has dropped with the policy change and then stayed stable (see Panel C in Figure 7), and the number of operating days per vessel has declined after 1989/90 (see Panel D in Figure 7). The more effective use of labor that we uncover is in line with 
anecdotes according to which boat-owners took turns in working at each other's boat. Such beneficial trade was only possible once harvest was secured through individual quotas.

$$
\text { [Insert Figure } 7 \text { here.] }
$$

In addition to the cost-saving changes in fuel- and labor use, we observe a more efficient adaption of the output structure over time. The simultaneous increase in the variance of cod harvest per boat with its mean indicates that the quota was initially binding for all vessels, but as the quota increased this constraint became non-binding for an increasing number of vessels that also target other species. ${ }^{19}$ Further evidence for an increased specialization in harvest can be found when analyzing the histograms of the share of cod in the total harvest before and after the policy change (Panel A in Figure 8). The mean of these two distributions is virtually the same ( 0.455 before and 0.458 after the intervention, see also Table A-1 in the Appendix), but the distribution is single-peaked before 1990 and bi-modal after the introduction of individual quotas. The hump at the lower end of the distribution after the policy change is clearly related to the requirement to catch a certain fraction of the annual quota in order to stay among the vessels that are granted a quota in the next year (Group I). For those vessels that shift away from targeting cod, there is no clear pattern to which fishery they rather turn. Some turn to pelagic species, some to saithe and flatfish, and for others again the value of "other species" increases (which most likely means participation in the emerging crab fisheries).

Furthermore, Figure 8 -B reveals something very interesting, namely that the participation in the seasonal fishery around Lofoten increased after the introduction of quotas. ${ }^{20}$ Harvesting the spawning stock around the Lofoten archipelago has always been the most lucrative (and most competitive) part of the Norwegian cod fishery. The marked increase in participation points to the important effect of asset security. With their individual quota in hand, more fishers found it now worthwhile to take the trip to Lofoten. Incidentally, the Lofoten reports ("Årsberetning vedkommende Norges Fiskerier", Norwegian Directorate of Fisheries, 1990) also mention a marked decrease in damages, gear collisions, and violations of area restrictions as a welcome side-effect of the individual quota system.

$$
\text { [Insert Figure } 8 \text { here.] }
$$

Finally, we document adjustments in the fleet structure that led to an increase in average profits: First, we compare vessels that enter the fishery (either by replacing exiting vessels 
or through the limited rounds of "recruitment" sanctioned by the authorities) with the stock of existing vessels (Table A-2 in the Appendix). There are 36 newly built vessels in our post-policy sample and an additional number of 10 vessels that enter the Directorate's boat registry from other sources (most likely purchased abroad). These 46 vessels are of course more modern, but they are also larger (in terms of tonnage, not length). They employ about the same amount of labor and effort (in terms of operating days), but they harvest significantly more, and are less specialized in catching cod. The annual profits of these new vessels is higher than the average of the incumbent vessels in 6 out of 8 years.

Second, we show that adjustments within the fleet of existing vessels led to higher profits. In total, there are 225 ownership transition recorded in our dataset. Figure 8 -C shows how the rate of ownership transitions increases from close to zero to about $30-40$ boat sales per year after 1994. For 72 of these transitions, we observe the same vessel both when operated by the old and the new owner. When regressing the Cobb-Douglas profit function (controlling for the identity of the individual vessel) where we include a dummy variable that is set to 0 for the old owner and set to 1 for the new owner, the coefficient for this variable is positive and significant at the $10 \%$ level (see Table A-5 in the Appendix). Thus, vessels that have changed owners are operated more profitably by their new owners than by their old owners.

Investigating the effect of the 1989/1990 policy change on investment pattern and industry dynamics (Nøstbakken, 2012; Schnier and Felthoven, 2013) is an important task for further research, especially as the introduction of private rights to exploit public resources was (and still is) a contested political issue. The finding that new owners operate their boats more profitably than old owners, for example, speaks against the wide-spread practice of "grandfathering" harvesting rights to existing firms, at least when there are reasons to believe that industry exit is sluggish or transferability of quota rights is limited. Auctioning harvest rights, in contrast, would not only improve efficiency in this regard, it could also reduce the contention that a select group of right-holders benefit from a resource that belongs to the "public". At the same time, it would be naïve to think that the transfer of wealth implied by an auctioning mechanism would not meet the fierce opposition of the affected groups.

In sum, moving from a situation of de-facto open-access to an individual vessel quota system coupled with a more strictly enforced TAC has led to significant increase in profits; mainly because fishers adjusted inputs (including vessels) and outputs. Clearly, gains were 
higher towards the end than in the beginning, but calculating the average treatment effect and summing over the whole period 1990-97, we arrive at an efficiency gain of 980 thousand NOK per vessel (in 1998-value; 95\% C.I: 119-1,841 thousand NOK). Extrapolating to the population of conventional vessels that are operated year round, this makes an aggregated total of 745 million NOK (95\% C.I. 159-1,332 million NOK) over the 8 years from 1990-1997. ${ }^{21}$

\section{Conclusion}

Fisheries are maybe the canonical arena to investigate performance under various forms of institutional regimes: Theory tells that rents are dissipated and fish stocks are depleted under open-access (Gordon, 1954), while well-defined harvesting rights give rise to considerable profits and high stock values (Scott, 1955). Real-world processes are evidently much more complex than the theoretical dichotomy of rent-dissipation and rent-maximization. Nonetheless, cross-sectional studies have indeed identified negative effects of open-access (McWhinnie, 2009) and positive effects of secure rights-based management (Costello et al., 2008, Grainger and Costello, 2014). These studies document convincingly that policies which delineate harvesting rights to individual users are associated with better performance, but they do not address the causal mechanism at work. Clearly, the 1989/1990 policy change in the Norwegian coastal fishery for cod established a harvesting right that is far from the textbook example of perfect ITQs. ${ }^{22}$ In the spirit of program evaluation, we argue that introducing individual quotas and simultaneously enforcing the TAC improved the profitability of the coastal fisheries in Norway and strengthened its sustainability.

We find that the change from open-access to individual quotas and enforced TAC has had a significant, but comparatively small effect on the cod stock. The main part of the observed increases in the resource base appears to have been due to favorable environmental conditions.

Analyzing a detailed data-set over 13 years with information on vessel and owner characteristics, we show that the policy change led to a sizable increase (about 15\%) in the total short-run profits over the period from 1990-1997. Strongly put, an average vessel gained about one million NOK (in 1998 value) over the period 1990-1997 due to the policy reform. Because fishers had more secure harvesting rights after the policy change, they could avoid a costly race to fish and exploit gains from specialization as well as economize on labor inputs. The 
increase in profits unfolded over time: Initially the positive effects of the policy reform were outweighed by negative effect of a constrained harvest. With time, both the cod stock and individual quotas increased, so that overall profits became higher than they would have been without the policy change. 


\section{Appendix}

\section{A.1 Additional background information on Norwegian fisheries}

Figure A-1 shows the strong seasonal pattern and the relative contribution of cod, haddock, and saithe in the overall Norwegian landings.

[Insert Figure A-1 here]

Figure A-2 shows the stock of fishing vessels registered in Norway. The overall declining trend is mainly caused by the retirement of open vessels and decked vessels below $13 \mathrm{~m}$ length (See the left panel of Figure A-2 that shows the cumulative plot of all registered vessels). Of the boats larger than $13 \mathrm{~m}$, the number of conventional boats that fish year-round begin, in fact, to increase slightly after 1990 (See the right panel of Figure A-2 that zooms in on the boats larger than 13m). Boats smaller than $13 \mathrm{~m}$ make up between $91 \%$ (in 1985) and 89\% (in 1997) of all registered vessels, but they contribute only between $6 \%$ (in 1985) and $2 \%$ (in 1997) to the overall landings in terms of volume and between $9 \%$ (in 1985) and 4\% (in 1997) in terms of value.

\section{[Insert Figure A-2 here.]}

Figure A-3 presents an overview of recommended and agreed quotas and actual catches (in total; data from Hønneland, 2006). It shows clearly how quotas had been too generous in the 1980s. They exceeded the scientific advice, which was already overly optimistic during that period (Nakken, 1998). The actual harvest was almost always still higher. While this pattern also holds for the most part of the 1990s, the magnitude of the excess is much smaller.

\section{[Insert Figure A-3 here.]}

Figure A-4 shows the agreed TAC and actual harvest differentiated after countries and vessel categories. In particular, the Figure shows how the pattern of overfishing changed. Before the policy change in 1989/90, overfishing was almost exclusively due to Norwegian vessels, in particular the conventional fleet. In turn, this fleet did not exceed their quota a single time after 1990. Rather, vessels from Russia and other countries, as well as illegal, unregulated, and unreported (IUU) harvest caused the observed overfishing. Note that there is no single source for this data, but we have compiled the data in Figure A-4 by comparing information from Nærings og Fiskeridepartementet (1998); Aglen et al. (2005); Zilanov (2005); Hønneland (2006); ICES (2012) and Statistisk Sentralbyrå $(1998,1999,2000)$. There are some discrepancies in the various sources for the periods that their data overlaps, which can in part be attributed to different ways of accounting for quota exchanges and reported catches. We have tried our best to commensurate the information, but the presentation should be treated with 
some caution. In particular, the category "other countries and IUU" contains a residual post of harvest from other countries and IUU harvest, that may have also been caught by Norwegian or Russian fishing vessels.

[Insert Figure A-4 here.]

Table A-1 and A-2 give summary statistics comparing subsamples of the data. The last column in each table gives the difference in means, where the stars indicate statistical significance (Welch two sample t-test).

Table A-1: Summary statistics comparing the sample before and after the policy change

\begin{tabular}{|c|c|c|c|c|c|c|c|}
\hline \multirow[b]{2}{*}{ Statistic } & \multicolumn{3}{|c|}{ (1) Sample 1985-1989 } & \multicolumn{3}{|c|}{ (2) Sample 1990-1997 } & \multirow{2}{*}{$\begin{array}{c}(2)-(1) \\
\text { Diff. }\end{array}$} \\
\hline & $\mathrm{N}(\mathrm{n})$ & Mean & St. Dev. & $\mathrm{N}(\mathrm{n})$ & Mean & St. Dev. & \\
\hline Length (meter) & $578(282)$ & 17.19 & 3.37 & $1240(509)$ & 17.21 & 3.61 & 0.019 \\
\hline Tonnage (BRT) & $578(282)$ & 38.91 & 29.09 & $1240(509)$ & 45.49 & 39.83 & $6.579^{* * *}$ \\
\hline Boat-age (in years) & $577(281)$ & 21.79 & 15.04 & $1240(509)$ & 22.15 & 16.30 & 0.357 \\
\hline Labor (Man-years) & $578(282)$ & 4.46 & 1.65 & $1240(509)$ & 4.18 & 1.58 & $0.280^{* * *}$ \\
\hline Operating days per year & $578(282)$ & 286.31 & 39.69 & $1240(509)$ & 275.08 & 46.45 & $11.232^{* * *}$ \\
\hline Harvest (in metric tons) & $578(282)$ & 250.96 & 224.04 & $1240(509)$ & 423.35 & 467.15 & $172.39^{* * *}$ \\
\hline Share of cod in harvest & $578(282)$ & 0.46 & 0.24 & $1240(509)$ & 0.46 & 0.24 & 0.004 \\
\hline Revenue (1000 NOK) & $578(282)$ & 1763.66 & 1343.70 & $1240(509)$ & 2067.64 & 1472.88 & $303.98^{* * *}$ \\
\hline Total cost (1000 NOK) & $578(282)$ & 1664.95 & 1246.34 & $1240(509)$ & 1913.13 & 1305.98 & $248.18^{* * *}$ \\
\hline Variable cost (1000 NOK) & $578(282)$ & 1054.58 & 793.81 & $1240(509)$ & 1196.00 & 817.80 & $141.43^{* * *}$ \\
\hline
\end{tabular}

Table A-2: Summary statistics comparing entering vessels with the remaining sample

\begin{tabular}{|c|c|c|c|c|c|c|c|}
\hline \multirow[b]{2}{*}{ Statistic } & \multicolumn{3}{|c|}{ (1) Sample excluding entering vessels } & \multicolumn{3}{|c|}{ (2) Entering vessels } & \multirow{2}{*}{$\begin{array}{c}(2)-(1) \\
\text { Diff. }\end{array}$} \\
\hline & $\mathrm{N}(\mathrm{n})$ & Mean & St. Dev. & $\mathrm{N}(\mathrm{n})$ & Mean & St. Dev. & \\
\hline Length (meter) & $1716(622)$ & 17.22 & 3.55 & $102(46)$ & 16.86 & 3.25 & -0.359 \\
\hline Tonnage (BRT) & $1716(622)$ & 42.67 & 36.09 & $102(46)$ & 55.68 & 46.74 & $13.01^{* * *}$ \\
\hline Boat-age (in years) & $1715(621)$ & 22.91 & 15.78 & $102(46)$ & 7.25 & 9.54 & $-15.66^{* * *}$ \\
\hline Labor (Man-years) & $1716(622)$ & 4.27 & 1.61 & $102(46)$ & 4.22 & 1.54 & -0.051 \\
\hline Operating days per year & $1716(622)$ & 278.62 & 44.68 & $102(46)$ & 279.02 & 45.37 & 0.395 \\
\hline Harvest (in metric tons) & $1716(622)$ & 355.19 & 399.44 & $102(46)$ & 593.10 & 562.68 & $237.91^{* * *}$ \\
\hline Share of cod in harvest & $1716(622)$ & 0.46 & 0.24 & $102(46)$ & 0.37 & 0.22 & $-0.09^{* *}$ \\
\hline Revenue (1000 NOK) & $1716(622)$ & 1939.57 & 1424.15 & $102(46)$ & 2499.56 & 1596.77 & $559.98^{* * *}$ \\
\hline Total cost (1000 NOK) & $1716(622)$ & 1804.88 & 1276.71 & $102(46)$ & 2327.95 & 1448.83 & $523.06^{* * *}$ \\
\hline Variable cost (1000 NOK) & $1716(622)$ & 1136.06 & 803.93 & $102(46)$ & 1403.11 & 916.51 & $267.06^{* * *}$ \\
\hline
\end{tabular}

\section{A.2 The stock-harvest relationship in the biomass simulation model}

Table A-3 gives the parameter values of the model we employed in the simulation (Model 1) as well as several simple alternative models that we have considered (Model 3-5). Interestingly, the average price of $\operatorname{cod} \hat{p}_{t}$ (instrumented by the price of the previous year ${ }^{23}$ ) did not turn out to be significant. The linear model (1) and the log-log model (5) both yield a better fit than the other models (judgded by $R^{2}$ and $\mathrm{AIC}$ ). Their goodness-of-fit is practically indistinguishable from another, so that we use the simplest model, Model 1, which also soundly passes the Durbin-Watson test (dw-statistic of 1.98). 
Table A-3: Regression results of harvest on total biomass

\begin{tabular}{|c|c|c|c|c|c|}
\hline$H_{t}$ & $\begin{array}{l}\text { Model } 1 \\
\alpha+\beta B_{t}\end{array}$ & $\begin{array}{c}\text { Model } 2 \\
\alpha+\beta \ln \left(B_{t}\right)\end{array}$ & $\begin{array}{c}\text { Model } 3 \\
\alpha+\beta B_{t}+\gamma B_{t}^{2}\end{array}$ & $\begin{array}{c}\text { Model } 4 \\
\alpha+\beta B_{t}+\gamma \hat{p}_{t}\end{array}$ & $\begin{array}{c}\text { Model } 5 \\
\ln \left(H_{t}\right)=\alpha+\beta \ln \left(B_{t}\right)\end{array}$ \\
\hline Intercept & $\begin{array}{c}-24.07 \\
(54.70)\end{array}$ & $\begin{array}{c}-3665.87^{* * *} \\
(384.14)\end{array}$ & $\begin{array}{c}-116.76 \\
(192.48)\end{array}$ & $\begin{array}{c}-243.47 \\
(231.08)\end{array}$ & $\begin{array}{c}-1.19 \\
(0.59)\end{array}$ \\
\hline Biomass $B_{t}$ & $\begin{array}{l}0.43^{* * *} \\
(0.04)\end{array}$ & & $\begin{array}{c}0.57 \\
(0.29)\end{array}$ & $\begin{array}{l}0.46^{* * *} \\
(0.05)\end{array}$ & \\
\hline $\ln \left(B_{t}\right)$ & & $\begin{array}{l}592.35^{* * *} \\
(53.54)\end{array}$ & & & $\begin{array}{l}1.04^{* * *} \\
(0.08)\end{array}$ \\
\hline$B_{t}^{2}$ & & & $\begin{array}{r}-4.75 \cdot 10^{-5} \\
9.45 \cdot 10^{-5}\end{array}$ & & \\
\hline Price $\hat{p}_{t}$ & & & & $\begin{array}{l}23.76 \\
(24.31)\end{array}$ & \\
\hline $\mathrm{N}$ & 20 & 20 & 20 & 20 & 20 \\
\hline$R^{2}$ & 0.89 & 0.86 & 0.87 & 0.88 & {$[0.88]^{1}$} \\
\hline AIC & 238.5 & 242.0 & 241.4 & 240.6 & {$[238.6]$} \\
\hline
\end{tabular}

Robust standard errors in parentheses, ${ }^{* * *} p<0.001,{ }^{* *} p<0.01,{ }^{*} p<0.05$

The parameters are estimated on ICES-data for the time from 1970 to 1989. The values for $H_{t}, H_{a, t}, B_{t}$, and $B_{a, t}$ are taken from Table 3.7. (catch weights) and Table 3.5 (catch numbers), as well as from Table 3.8. (stock weights) and Table 3.16 (Stock numbers) of the 2012 ICES report.

The ICES-data before the 1970's are generally considered to be less reliable (Ekerhovd and Gordon, 2013 p.384). Importantly, the chosen period also strikes a balance between obtaining sufficiently many observations and not extending the time series too far into the past when conditions may have been different, due to, for example, technological change. At the end of the day, the choice of 1970 as the starting year is somewhat arbitrary. We have therefore plotted the slope coefficient and the $\mathrm{R}^{2}$ value from Model 1 when taking different starting values (Figure A-5). As one would expect, the relationship appears to be different for the early 1960s before the sonar and the power block were introduced and diffused (Hannesson et al. 2010). Similarly, one can see how the precision of the estimate decreases as the degrees of freedom decline when one moves the starting date towards 1980. For different staring years around 1970, the slope coefficient varies very little and the explanatory power of the simple linear model is indeed very high.

\section{[Insert Figure A-5 here.]}

A possible concern could be that we use the harvest data from all boats, instead of explaining only the harvest from the Norwegian coastal vessels. While the harvest from these boats account for up to $70 \%$ of Norwegian harvest and about $32 \%$ of total harvest, they target in particular the spawning stock which has (by itself) important consequences for the future stock development. However, to simulate the development of the cod stock as close as possible, it is important to predict the entire harvest.

\footnotetext{
${ }^{1}$ Note that the $R^{2}$ and the AIC value of Model 1 and 5 are not directly comparable as the dependent variable of Model 5 is the logarithm of the dependent variable of Model 1. We have therefore calculated the predicted values from Model 5 as $\hat{H}_{t}=e^{\hat{\alpha}} * B_{t}^{\hat{\beta}}$ and accordingly based the AIC and the $R^{2}$ on the residuals $H_{t}-\hat{H}_{t}$.
} 
The policy change in 1989/90, that effectively ended overfishing from the coastal vessels (see Figure A-4, lead to a pronounced relief of pressure that the spawning stock was exposed to: The ratio of total harvest to the spawning stock biomass (SSB) is much larger and more volatile before 1990 (mean value of 3.17) than afterwards (mean value of 0.97); see Figure A-6 (A). Although the policy change in 1989/90 is not accompanied with a similarly clear reduction in overfishing for the other fleets (see Figure A-4, there are clear signs that the relationship between stock and harvest before and after 1989/90 is different. This is visualized by Panel (B) in Figure A-6 where the blue points and blue dashed line refer to the relationship before 1990 (in fact the regression line of Model 1 in Table A-3), the red diamonds and the red dotted line refer to the relationship after 1990 and the black solid line is the regression-line from the estimation that covers the entire period 1970 to 1997 . A Chow test rejects that there is a common relationship: The test statistics is 4.23 , which is larger than the relevant value at $5 \%$ significance $\left(F_{2 ; 28 ; 0.95}=3.35\right)$.

$$
\text { [Insert Figure A-6 here.] }
$$

Finally, one could ask why we have not used an explicit theoretical model to explain the relationship between the stock and aggregate harvest. For example, we could have employed the generalized Gordon-Schaefer harvest function $H=q E^{1-\alpha} B^{\beta}$. The main problem here is to find an appropriate proxy for effort $E$. The best available proxy for aggregate effort is the number of boats. But of course, the number of participating boats is hopelessly endogenous (Gordon, 2013). Hence one would have to explicitly model participation. This would not only add yet another layer of structural uncertainty to our projections, it would also come close to a catch 22 as one would use effort to explain the stock development and the stock biomass to explain effort.

\section{A.3 The stock-recruitment relationship in the biomass simulation model}

The recruitment relationship (4) is estimated by regressing equation $A-1$ with help of the non-linear least-squares routine "nls" in R 3.1.1 (2014) on the ICES recruitment data from 1946-2011. In addition, we have also estimated the model $\mathrm{A}-2$ with additive error. Table $\mathrm{A}-4$ shows the regression results.

$$
\begin{aligned}
\ln N_{3, t} & =\ln \left(\frac{e^{a} S S B_{t-3}}{1+e^{b} S S B_{t-3}}\right)+\ln \varepsilon_{t} \\
N_{3, t} & =\frac{e^{a} S S B_{t-3}}{1+e^{b} S S B_{t-3}}+\varepsilon_{t}
\end{aligned}
$$

As explained in the main text, the survival from egg to recruit can be viewed as the product of many smaller survival events, and we thus expect model A-1 to perform better. This is indeed confirmed when inspecting Figure A-7, which plots the distribution of the sample residuals against 
Table A-4: Regression results for recruitment function

\begin{tabular}{|c|c|c|}
\hline & Model A-1 & Model A-2 \\
\hline$a$ & $1.23^{* * *} \quad(0.29)$ & $1.97^{* * *} \quad(0.52)$ \\
\hline$b$ & $-5.69^{* * *} \quad(0.53)$ & $-4.79^{* * *} \quad(0.69)$ \\
\hline $\mathrm{N}$ & 61 & 61 \\
\hline$R^{2}$ & 0.21 & {$[0.11]$} \\
\hline AIC & 111.7 & [118.1] \\
\hline
\end{tabular}

the quantiles of the normal distribution. Also the $R^{2}$ and AIC in Table A-4 show that Model A-1 fits better (where we use the same transformation as in the harvest model to achieve comparability).

$$
\text { [Insert Figure A-7 here.] }
$$

\section{A.4 Validation of biomass simulation model}

In this section, we show the observed development of the cod stock from 1970 to 1990 (Figure A-8 and counterfactual stock dynamics when progressively more parts of the model are based on estimated relationship rather than observed values: The black line are the observed values (strictly speaking the results from the virtual-population analysis from ICES). The purple line plots the result from our model (equation (1) to (4) in section 4.1) when we use the actual observed harvest and recruitment values as inputs (the two lines are distinguishable, but very close). The next step is to show the projection result when we take the observed recruitment values but insert the counterfactual harvested values (red line). This stock projection already underestimates the stock in the 1970's and overestimated the stock in the 1980s, but it is at all time within the $95 \%$ confidence interval band of a simple firstorder autoregressive process. Finally, we show the simulation results when we follow our method, i.e. using estimated harvest and estimated recruitment. Not surprisingly, the error increases yet again, amplifying the difference between the ICES stock projection and our model. Now it is not within the 95\% confidence band for 3 out of 21 years $(1976,1977$, and 1978).

Note that we demand quite a bit by asking it to replicate the time series for 21 years when in the actual analysis we project the stock biomass forward for 7 years. Our main concern here is to see whether our projection method would broadly capture the overall trends in the data, which it does. But we do think that our validation exercise also points to the uncertainties that surround of projection method.

[Insert Figure A-8 here.] 


\section{A.5 Comparing observed and counterfactual profits for restricted sample}

As discussed in the main text, we have calculated the counterfactual profits also for the restricted sample of vessel-owner combinations that are observed both before and after the policy change. The result is shown in Figure $\mathrm{A}-9$

$$
\text { [Insert Figure A-9 here.] }
$$

\section{A.6 Profits of vessels that have changed owner}

In Table A-5, we present the results of a regression of the Cobb-Douglas profit function where we control for the identity of the individual vessel with a fixed effect and include a dummy variable that is set to 0 for the old owner and set to 1 for the new owner. The coefficient for this variable is positive and significant at the $10 \%$ level, showing that vessels are operated more profitably by their new owner than by their old owner.

Table A-5: Regression Results for Cobb-Douglas Profit Function for vessels that change owner

\begin{tabular}{lcc}
\hline & \multicolumn{2}{c}{ Dependent variable: $\ln \pi$} \\
\hline (Intercept) & -0.837 & $(1.406)$ \\
Cod price & 0.152 & $(0.179)$ \\
Dummy cod price & $0.507^{*}$ & $(0.270)$ \\
Haddock price & $0.617^{* * *}$ & $(0.157)$ \\
Dummy haddock price & $-0.754^{* * *}$ & $(0.212)$ \\
Other price & 0.000678 & $(0.102)$ \\
Dummy other price & 0.0926 & $(0.110)$ \\
Labor & $1.365^{* * *}$ & $(0.193)$ \\
Dummy labor & $-0.929^{* * *}$ & $(0.170)$ \\
Fuel price & $0.502^{* * *}$ & $(0.145)$ \\
Dummy fuel price & -0.0936 & $(0.190)$ \\
Cod biomass & $0.274^{* *}$ & $(0.114)$ \\
Indiv. quota & $0.413^{* * *}$ & $(0.0784)$ \\
Dummy newowner & $0.106^{*}$ & $(0.0630)$ \\
\hline $\mathrm{N}$ & $336(72)$ & \\
$R^{2}$ & 0.56 & \\
AIC & 235 & \\
\hline Fixed-effect within regression; ${ }^{*} p<0.10,{ }^{* *} p<0.05,^{* * *} p<0.01$ \\
(Standard errors in parentheses, clustered at the boat-level) \\
\end{tabular}




\section{References}

Abadie, A. and Gardeazabal, J. (2003). The economic costs of conflict: A case study of the basque country. American Economic Review, 93(1):113-132.

Abbott, J. K., Garber-Yonts, B., and Wilen, J. E. (2010). Employment and remuneration effects of ifqs in the bering sea/aleutian islands crab fisheries. Marine Resource Economics, 25(4):333-354.

Aglen, A., Nakken, O., Yaragina, N. A., and Sokolov, K. (2005). Retrospective review of management advice for northeast arctic cod. Joint Report Series 2, IMR/PINRO.

Anon. (2011). Survey report from the joint norwegian/russian ecosystem survey in the barents sea augustoctober 2011. Joint Report Series 3/2011, IMR/PINRO.

Årland, K. and Bjørndal, T. (2002). Fisheries management in Norway-an overview. Marine Policy, 26(4):307313.

Armstrong, C. W., Eide, A., Flaaten, O., Heen, K., and Kaspersen, I. W. (2014). Rebuilding the northeast arctic cod fisheries economic and social issues. Arctic Review on Law and Politics, 5(1):11-37.

Armstrong, C. W. and Sumaila, U. R. (2001). Optimal Allocation of TAC and the Implications of Implementing an ITQ Management System for the North-East Arctic Cod. Land Economics, 77(3):350-359.

Arnason, R. (2005). Property rights in fisheries: Iceland's experience with itqs. Reviews in Fish Biology and Fisheries, 15(3):243-264.

Asche, F. (2009). Adjustment cost and supply response in a fishery: A dynamic revenue function. Land Economics, 85(1):201-215.

Asche, F., Bjørndal, T., and Gordon, D. V. (2009). Resource rent in individual quota fisheries. Land Economics, 85(2):279-291.

Asche, F., Kumbhakar, S. C., and Tveterås, R. (2007). Testing cost vs. profit function. Applied Economics Letters, 14(10):715-718.

Bogstad, B., Yaragina, N. A., and Nash, R. D. (2016). The early life-history dynamics of northeast arctic cod: levels of natural mortality and abundance during the first 3 years of life. Canadian Journal of Fisheries and Aquatic Sciences, 73(2):246-256.

Branch, T. A. (2009). How do individual transferable quotas affect marine ecosystems? Fish and Fisheries, 10(1):39-57.

Bromley, D. W. (2009). Abdicating responsibility: The deceits of fisheries policy. Fisheries, 34(6):280-302.

Bromley, D. W. (2016). Rights-based fisheries and contested claims of ownership: Some necessary clarifications. Marine Policy, 72:231 - 236.

Christensen, P. and Hallenstvedt, A. (2005). I kamp om havets verdier : Norges fiskarlags historie. Norges Fiskarlag, Trondheim.

Chu, C. (2009). Thirty years later: the global growth of itqs and their influence on stock status in marine fisheries. Fish and Fisheries, 10(2):217-230.

Costello, C., Gaines, S. D., and Lynham, J. (2008). Can catch shares prevent fisheries collapse? Science, 321(5896):1678-1681.

Croissant, Y. and Millo, G. (2008). Panel data econometrics in R: The plm package. Journal of Statistical Software, 27(2).

Diekert, F. K. (2012). Growth overfishing: The race to fish extends to the dimension of size. Environmental and Resource Economics, 52(4):549-572.

Diekert, F. K., Hjermann, D. Ø., Nævdal, E., and Stenseth, N. C. (2010). Spare the young fish: Optimal harvesting policies for north-east arctic cod. Environmental and Resource Economics, 47:455-475.

Dupont, D. P., Fox, K. J., Gordon, D. V., and Grafton, R. Q. (2005). Profit and price effects of multi-species individual transferable quotas. Journal of Agricultural Economics, 56(1):31-57.

Eide, A. (2007). Economic impacts of global warming: The case of the barents sea fisheries. Natural Resource Modeling, 20(2):199-221.

Ekerhovd, N.-A. and Gordon, D. V. (2013). Catch, stock elasticity, and an implicit index of fishing effort. Marine Resource Economics, 28(4):379-395.

Fox, K. J., Grafton, R., Kirkley, J., and Squires, D. (2003). Property rights in a fishery: regulatory change and firm performance. Journal of Environmental Economics and Management, 46(1):156-177.

Godø, O. R. (2003). Fluctuation in stock properties of North-East Arctic cod related to long-term environmental changes. Fish and Fisheries, 4(2):121-137.

Gómez-Lobo, A., Peña Torres, J., and Barría, P. (2011). Itq's in chile: Measuring the economic benefits of 
reform. Environmental and Resource Economics, 48(4):651-678.

Gordon, D. V. (2013). The endogeneity problem in applied fisheries econometrics: A critical review. Environmental and Resource Economics, online:1-11.

Gordon, H. S. (1954). The Economic Theory of a Common-Property Resource: The Fishery. Journal of Political Economy, 62(2):124-142.

Grafton, R., Squires, D., and Fox, K. (2000). Private property and economic efficiency: a study of common-pool resource. Journal of Law and Economics, 43:679.

Grainger, C. A. and Costello, C. J. (2014). Capitalizing property rights insecurity in natural resource assets. Journal of Environmental Economics and Management, forthcoming(0):-.

Gullestad, P., Aglen, A., Bjordal, r., Blom, G., Johansen, S., Krog, J., Misund, O. A., and Røttingen, I. (2014). Changing attitudes 19702012: evolution of the norwegian management framework to prevent overfishing and to secure long-term sustainability. ICES Journal of Marine Science, 71(2):173-182.

Guttormsen, A. G. and Roll, K. H. (2011). Technical efficiency in a heterogeneous fishery: The case of norwegian groundfish fisheries. Marine Resource Economics, 26(4):293-307.

Hannesson, R. (1983). Optimal harvesting of ecologically interdependent fish species. Journal of Environmental Economics and Management, 10(4):329-345.

Hannesson, R. (2013). Norway's experience with ITQs. Marine Policy, 37(0):264-269.

Hannesson, R., Salvanes, K. G., and Squires, D. (2010). Technological change and the tragedy of the commons: The lofoten fishery over 130 years. Land Economics, 86(4):746-765.

Hersoug, B. (2005). Closing the commons: Norwegian fisheries from open access to private property. Eburon, Delft.

Hersoug, B., Holm, P., and Rånes, S. A. (2000). The missing t. path dependency within an individual vessel quota system -?? the case of norwegian cod fisheries. Marine Policy, 24(4):319-330.

Hjermann, D. Ø., Bogstad, B., Eikeset, A. M., Ottersen, G., Gjøsæter, H., and Stenseth, N. C. (2007). Food web dynamics affect Northeast Arctic cod recruitment. Proceedings of the Royal Society B: Biological Sciences, 274(1610):661-669.

Holm, P. and Nielsen, K. N. (2007). Framing fish, making markets: the construction of individual transferable quotas (itqs). Sociological Review, 55(s2):173-195.

Hønneland, G. (2006). Kvotekamp og kyststatssolidaritet: norsk-russisk fiskeriforvaltning gjennom 30 A r. Fagbokforlag, Bergen.

ICES (2012). Report of the Arctic Fisheries Working Group (AFWG). Technical report, International Council for the Exploration of the Sea (ICES), Copenhagen, Denmark.

Kjesbu, O. S., Bogstad, B., Devine, J. A., Gjøsæter, H., Howell, D., Ingvaldsen, R. B., Nash, R. D. M., and Skjæraasen, J. E. (2014). Synergies between climate and management for atlantic cod fisheries at high latitudes. Proceedings of the National Academy of Sciences, early view.

Kumbhakar, S. C., Asche, F., and Tveteras, R. (2013). Estimation and decomposition of inefficiency when producers maximize return to the outlay: an application to norwegian fishing trawlers. Journal of Productivity Analysis, pages 1-15.

Kvamsdal, S. and Sandal, L. K. (2012). The ensemble kalman filter in bioeconomics. Discussion paper 5, Norwegian School of Economics, NHH, Bergen, Norway.

Lau, L. (1978). Applications of profit functions. In Fuss, M. and McFadden, D., editors, Production Economics: A Dual Approach to Theory and Applications, volume 1. North-Holland, Amsterdam.

McWhinnie, S. (2006). The impact of rights-based management regimes on fishery productivity. In Sumaila, U. R. and Marsden, A. D., editors, 2005 North American Association of Fisheries Economists Forum Proceedings, volume 14(1) of Fisheries Centre Research Reports, pages 77-86, Fisheries Centre, the University of British Columbia, Vancouver, Canada.

McWhinnie, S. F. (2009). The tragedy of the commons in international fisheries: An empirical examination. Journal of Environmental Economics and Management, 57(3):321-333.

Mideksa, T. K. (2013). The economic impact of natural resources. Journal of Environmental Economics and Management, 65(2):277-289.

Nærings og Fiskeridepartementet (1998). St.meld. nr. 51 (1997-98): Perspektiver på utvikling av norsk fiskerinæring. Technical report, The Norwegian Parliament (Stortinget).

Nakken, O. (1998). Past, present and future exploitation and management of marine resources in the barents sea and adjacent areas. Fisheries Research, 37:23-35(13).

Norwegian Directorate of Fisheries (annually). Lønnsomhetsundersøkelser for 
helårsdrivende fiskefartøy. Technical report, Fiskeridirektoratet, Bergen, Norway. wWw.fiskeridir.no/statistikk/fiskeri/loennsomhetsundersoekelse-for-fiskeflaaten/ loennsomhetsundersoekelse-for-fiskefartoey-publikasjoner.

Norwegian Directorate of Fisheries (1990). Årsberetning vedkommende norges fiskerier: Lofotfiske. Technical report, Fiskeridirektoratet, Bergen, Norway. http://brage.bibsys.no/xmlui/handle/11250/273705.

Nøstbakken, L. (2012). Investment drivers in a fishery with tradable quotas. Land Economics, 88(2):400-424.

NOU (2002). Eierskap til fiskefartøy. utredning fra eierskapsutvalget oppnevnt ved kongelig resolusjon av 8. juni 2001. Technical report, Fiskeridepartementet.

Ohlberger, J., Rogers, L. A., and Stenseth, N. C. (2014). Stochasticity and determinism: How densityindependent and density-dependent processes affect population variability. PLoS ONE, 9(6):e98940.

Ottersen, G., Helle, K., and Bogstad, B. (2002). Do abiotic mechanisms determine interannual variability in length-at-age of juvenile arcto-norwegian cod? Canadian Journal of Fisheries and Aquatic Sciences, 59:57-65.

Quinn, T. J. . and Deriso, R. B. (1999). Quantitative fish dynamics. Oxford, New York.

R 3.1.1 (2014). R: A Language and Environment for Statistical Computing. R Foundation for Statistical Computing, Vienna, Austria. http://www.R-project.org.

Reimer, M. N., Abbott, J. K., and Wilen, J. E. (2014). Unraveling the multiple margins of rent generation from individual transferable quotas. Land Economics, 90(3):538-559.

Rouyer, T., Ottersen, G., Durant, J. M., Hidalgo, M., Hjermann, D. Ø., Persson, J., Stige, L. C., and Stenseth, N. C. (2011). Shifting dynamic forces in fish stock fluctuations triggered by age truncation? Global Change Biology, 17(10):3046-3057.

Scheld, A., Anderson, C., and Uchida, H. (2012). The economic effects of catch share management: The rhode island fluke sector pilot program. Marine Resource Economics, 27(3):203-228.

Schnier, K. E. and Felthoven, R. G. (2013). Production efficiency and exit in rights-based fisheries. Land Economics, 89(3):538-557.

Schweder, T. and Hjort, N. (2016). Confidence, Likelihood, Probability: Inference With Confidence Distributions. Cambridge University Press.

Scott, A. (1955). The Fishery: The Objectives of Sole Ownership. Journal of Political Economy, 63(2):116-124.

Squires, D. (1987). Long-run profit functions for multiproduct firms. American Journal of Agricultural Economics, 69(3):558-569.

Standal, D. and Aarset, B. (2002). The tragedy of soft choices: capacity accumulation and lopsided allocation in the norwegian coastal cod fishery. Marine Policy, 26(3):221-230.

Statistisk Sentralbyrå (2000). Official statistics of norway: Fishery statistics. Technical report. https: //www.ssb.no/fiskeri?fane=arkiv

Stokke, O. S., Anderson, L., and Mirovitskaya, N. (1999). The Barents Sea Fisheries. In Young, O. R., editor, The Effectiveness of International Environmental Regimes - Causal Connections and Behavioral Mechanisms, pages 91-154. MIT Press, Cambridge, Mass.

Zilanov, V. (2005). The use of tac as management measure in the barents sea. Joint Report Series 3, IMR/PINRO. 


\section{Notes}

1 Scheld et al. (2012) can use the synthetic control method because in their case there were indeed some boats in the fishery that participated in the program while others did not, and they can convincingly make the case that the other boats had no incentive, and indeed did not, change their behavior. Moreover, they can abstract from the biological aspects because they focus on within-season dynamics. In our case, all boats were directly or indirectly affected by the policy, and the biological dynamics are a key aspect of our study.

${ }^{2}$ In practice, there have been quota exchanges so that the actual division varied somewhat over the years, but the principal agreement on a 50-50 division of the stock is important: It frees the annual negotiations from the frictions that arise from allocational bargaining. The successful cautious cooperation in the arena of fisheries management must be seen in light of the Cold War, where Russia and Norway stood on either side of the Iron Curtain, the exact borders in the Barents Sea were disputed, and the fact that a large number of nuclear submarines were deployed in the area (Stokke et al., 1999).

${ }^{3}$ In fact, up to 1984 the quota agreements between Russia (Soviet Union at that time) and Norway stipulated explicitly that the conventional vessels could continue to catch cod even when the total quota was filled. This was repeatedly criticized by the Russian delegation, and the Norwegian authorities yielded to the pressure in the Joint Commission by issuing time restrictions on when harvesting was allowed. Fishing was then prohibited on some Sundays and Holidays in the year and these restrictions had little actual effect. Nevertheless, as a matter of principle, they led to strong protests from the coastal fishers.

${ }^{4}$ We thank Peter Gullestad for valuable discussions on the background of the policy change in 1989/90.

${ }^{5}$ There were in total about 3,500 boats in the Group I in the period we consider (NOU, 2002), while there were about 15,000 boats in the entire vessel registry (which includes both industrial trawlers as well as a large stock of small open vessels, see Figure A-2 in the Appendix for details). As we will describe below, we base our analysis on a sample of boats between $13 \mathrm{~m}$ and $28 \mathrm{~m}$ that are operated year-round and use conventional gears (that is, not trawl or purse seine). Nine out the 588 boat-owner combinations in our sample belong to Group II.

${ }^{6}$ In general, it was not the case that management was absent before 1989 and perfect afterwards, but rather it was in a state of flux during this period (Gullestad et al., 2014). Nevertheless, 1989/90 is recognized as "the great divide" in Norwegian fishery management (Standal and Aarset, 2002). Another regulatory change in 1989/90 that is worth mentioning is the introduction of a guideline for the division of the Norwegian TAC, the so called "trawl ladder". According to this allocation key, the trawlers obtained between 20 and $35 \%$ of the TAC, depending on its overall size. In order to protect the coastal vessels, the share that was given to the trawler was the smaller, the smaller the TAC.

${ }^{7}$ For further information on Norwegian fishery regulation, see Årland and Bjørndal (2002) or Gullestad et al. (2014). Hannesson (2013) gives a recent account of Norway's experience with ITQs in the pelagic and demersal fisheries, arguing that the resource rent has been capitalized in boat and quota values. Armstrong et al. (2014) give a good overview of the economic and social issues surrounding the rebuilding of the cod fishery. The Norwegian cod fishery has generally been a popular study object in the economic literature, from the early work on productivity (Hannesson, 1983) to its latest advances (Kumbhakar et al., 2013). It has 
served as example for calibrated simulations of e.g. the effect of cannibalism (Armstrong and Sumaila, 2001), the importance of age-differentiated management (Diekert et al. 2010), multi-species aspects (Kvamsdal and Sandal, 2012), or climate change effects (Eide, 2007). The profitability surveys from the Norwegian Directorate of Fisheries are often used in empirical applications. Asche and coauthors (Asche et al. 2009, Asche, 2009) study the trawler segment of the fishery to estimate the size of the resource rent (using data from 1997 and 1998) and to test for adjustment cost (using data from 1986-1994). Data from 1995-2007 for the entire demersal fleet has been used by Guttormsen and Roll (2011) to investigate technical inefficiencies. McWhinnie (2006) uses data for the coastal fleet from 1985-2000 to investigate productivity changes by means of index-number decomposition. Here, we use data from 1985-1997: As the sampling methodology changed in 1998, it is not advisable to extend a dataset that covers the 1989/90 policy change further than 1997.

${ }^{8}$ The Directorate of Fisheries published annual reports on the basis of these surveys, where aggregated statistics for the different vessel categories (mainly differentiated by length, gear, and main target species) are being presented. In these reports, the Directorate writes that the sample attrition is considered random and not related to the income- or cost-level. In 1982, the Directorate made an extensive effort to compare the category-level information in the surveys with other sources, such as the sales register and the social insurance scheme. It has found only very small deviations. This effort was repeated in 1988 and larger deviations both in positive and negative direction - were found, especially for categories that consist of very few vessels. The concerns that the categorization was no longer representative persisted even after a re-grouping in 1994 and the sampling methodology was changed: From 1998 on, the survey was only sent out to a selected sample and reporting was made mandatory (the actual information provided was of course still self-reported). Using the fact that we can identify individual boat owners (see below), we have compared profits from owners that report both in the three years before 1998 and in the years 1998-2000 and have found no significant difference (although reported profits in the latter period are somewhat larger).

${ }^{9}$ Specifically, the time series of prices for Number 2 heating oil, the closest to bunker fuel, issued by the US Energy Information Administration: https://www.eia.gov/forecasts/steo/realprices/. Norwegian heating oil prices, available through the Norwegian statistical bureau, are too much influenced by climatic idiosyncrasies in Oslo and other large cities.

${ }^{10}$ Table 03014: Konsumprisindeks; available at: https://www.ssb.no/statistikkbanken

${ }^{11}$ To be precise, we group "work compensation", "provisions", "social cost", "retirement contributions" "fuel cost", "bait, ice, salt, and packaging", and "product tax" as variable cost, whereas vessel depreciation, maintenance, as well as "other cost" (such as for external accounting services etc.) are grouped as fixed costs.

${ }^{12}$ Indeed, the data shows no signs of systematic changes in the selectivity pattern. Diekert (2012) gives a theoretical argument that aggregate ITQs per se do not influence the incentives for changing gear selectivity.

${ }^{13}$ The spawning stock biomass is calculated as $S S B_{t}=\sum_{a} m a t_{a, t} w_{a, t} N_{a, t}$ where mat $_{a, t}$ is the proportion of mature individuals in a given cohort (obtained from Table 3.10 in ICES, 2012).

${ }^{14}$ Note that the residual would also pick up changes in recruitment that are due to other policy changes that aimed at protecting juvenile fish but had no impact on harvest (such as stricter by-catch regulations in a related fishery). In their review of the management of this fishery, Aglen et al. (2005) mention the following changes: 
In 1984 efforts were undertaken to limit the by-catch of juvenile Gadidae in the shrimp fishery. In 1992, efforts were undertaken to limit the by-catch in the capelin fishery and in 1993, a sorting grid was introduced in the shrimp fishery. However, by-catches in these fisheries are considered to be negligible in relation to other sources of juvenile mortality (Bogstad et al. 2016). In fact, the capelin stock was essentially collapsed in the period from 1993 to 1997.

${ }^{15}$ A "transcendental logarithmic (translog) function" (Lau, 1978, Squires, 1987) is more flexible and allows to account for second-order interaction effects, but it is not useful for extrapolating in our case (due to overfitting). Additionally, the Cobb-Douglas function has the advantage that the elasticities are directly obtained from the estimates of the regression coefficients.

${ }^{16}$ As pointed out by Gordon (2013), constructing a fuel price proxy by dividing fuel expenditures by e.g. some measure of boat size does not help, as it would just let the endogeneity problem slip in through the backdoor (as fuel use is directly related to the effort used in catching fish).

${ }^{17}$ This is at least the case in the period that we have observed. The quota system might have had a much stronger effect in less favorable periods, e.g. by preventing depletion.

${ }^{18}$ We thank Frank Asche for discussion on this point.

${ }^{19} \mathrm{An}$ additional reason for the observed increase in spread in harvest is that the difference between the quotas for small boats and large boats increased. For example, in 1990, the individual quota for vessels between 13m and $14 \mathrm{~m}$ was about 30 tons, for vessels between $19 \mathrm{~m}$ and $20 \mathrm{~m}$, and for vessels between $27 \mathrm{~m}$ and $28 \mathrm{~m}$, the quota was 62 tons. In 1994, vessels between $13 \mathrm{~m}$ and $14 \mathrm{~m}$ received a quota of 80 tons, whereas vessels between $19 \mathrm{~m}$ and $20 \mathrm{~m}$ received a quota of 157 tons and for vessels between $27 \mathrm{~m}$ and $28 \mathrm{~m}$, the quota was 219 tons. In 1997 , these numbers were 157 tons for vessels between $13 \mathrm{~m}$ and $14 \mathrm{~m}, 380$ tons for vessels between $19 \mathrm{~m}$ and $20 \mathrm{~m}$ and 530 tons for vessels between $27 \mathrm{~m}$ and $28 \mathrm{~m}$. However, this differentiation of quota increases is not sufficient to explain the spread in observed cod harvest per boat (Figure $7 \mathrm{~A}$ ).

${ }^{20}$ The fact that the participation in 1990 has increased compared to 1989 but not reached later levels can be explained by the reportedly adverse weather in that year (see Norwegian Directorate of Fisheries, 1990), as well as with the fisher's hesitant and observant reaction towards the new quota system.

${ }^{21}$ This number would be higher, but also more uncertain when extrapolating from the sample of boat-owner combinations that are observed both before and after the policy change: Total gains from the reform over the 8 year periods would then be at 765 million NOK with a $95 \%$ confidence interval of $-0.3-1,876$ million NOK.

${ }^{22}$ For a discussion of the legal concept of a "property right" and the question whether an ITQ can constitute such a right, see Bromley (2016).

${ }^{23}$ The first-stage model $p_{t}=\alpha+\beta p_{t-1}+\epsilon$ has an $R^{2}$ of 0.69 with coefficients $\alpha=2.34(1.02)$ and $\beta=$ $0.71(0.13)$. The coefficient for the lagged price is significant at the $1 \%$ level. 


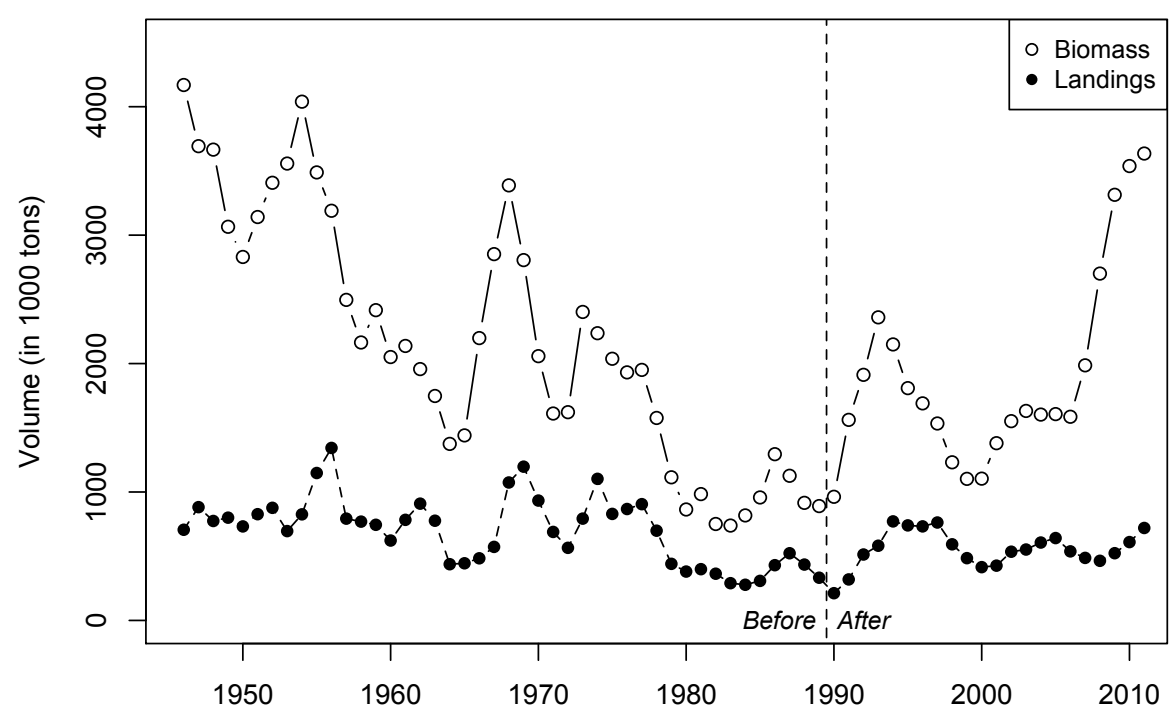

Figure 1: Observed biomass and total landings of North-East Arctic cod (1946-2012). The vertical dashed line indicates the 1989/90 policy change.

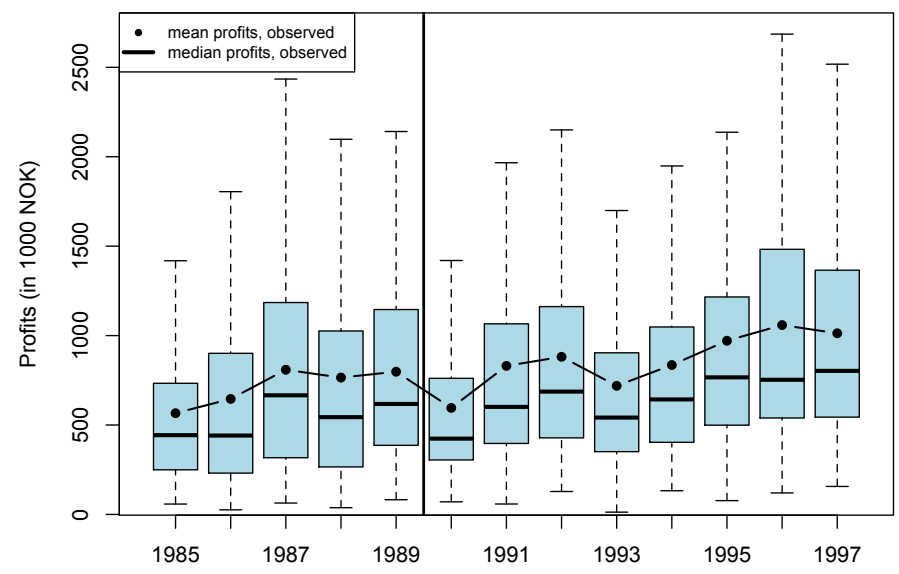

Figure 2: Boxplots of profits in units of 1000 real Norwegian Kroner (1998-value) from 1985 to 1997 

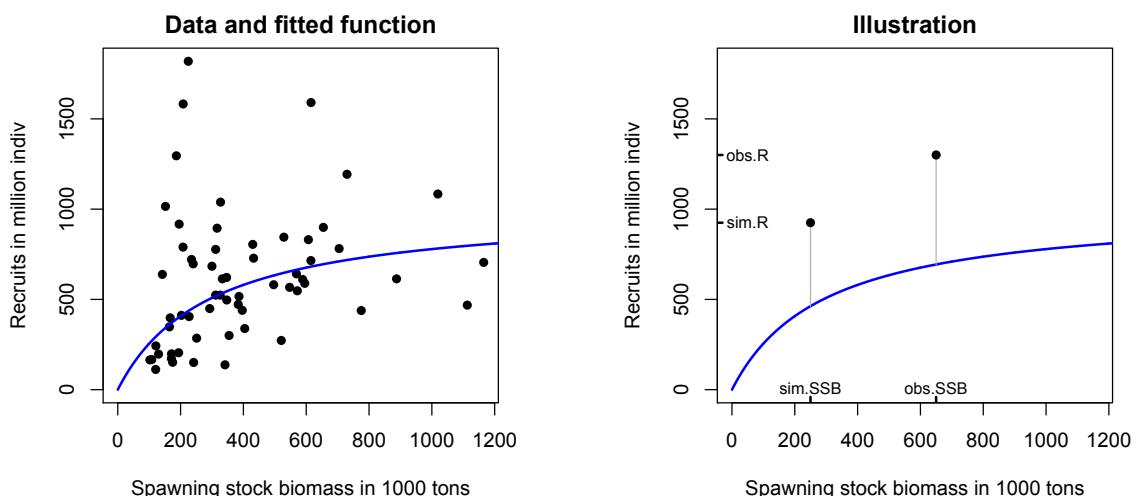

Figure 3: Stock-recruitment relationship (Data from 1946-2011). In the panel on the right, sim.SSB is the counterfactual counterfactual spawning stock while obs.SSB is the factual; sim.R is the counterfactual recruitment obtained from the stock recruitment function value at sim.SSB and accounting for the multiplicative residual from the pair (obs.SSB, obs.R).

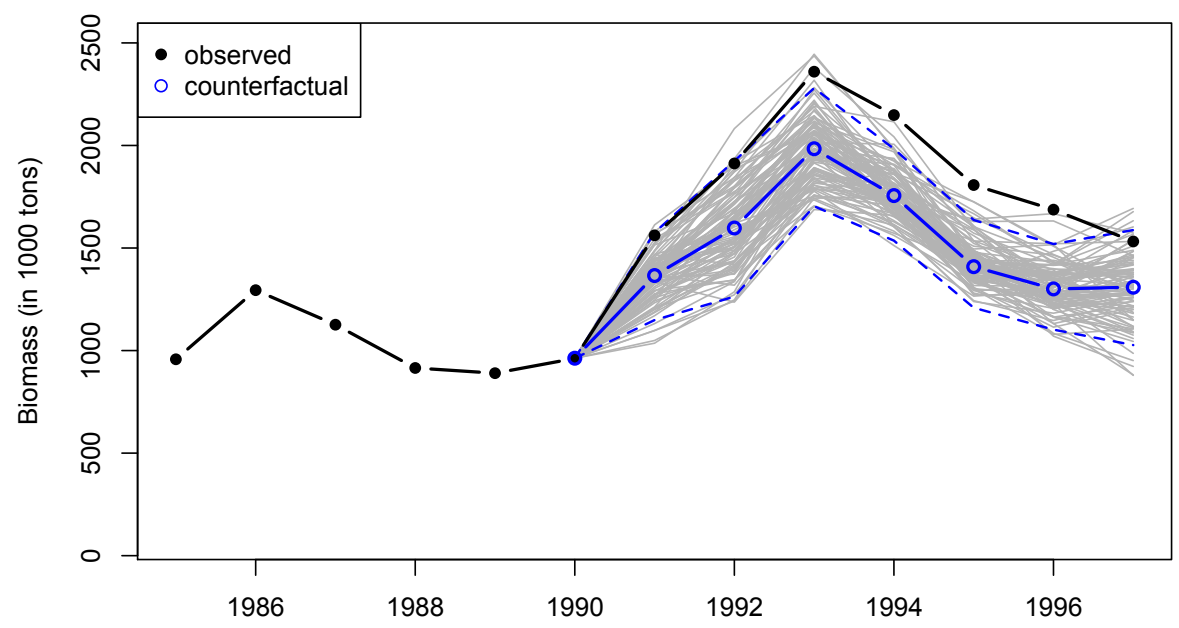

Figure 4: Observed values (black line) and counterfactual simulation of cod stock (blue line, open circles). The grey lines are re-sampled paths used to gauge the uncertainty of the simulation. 


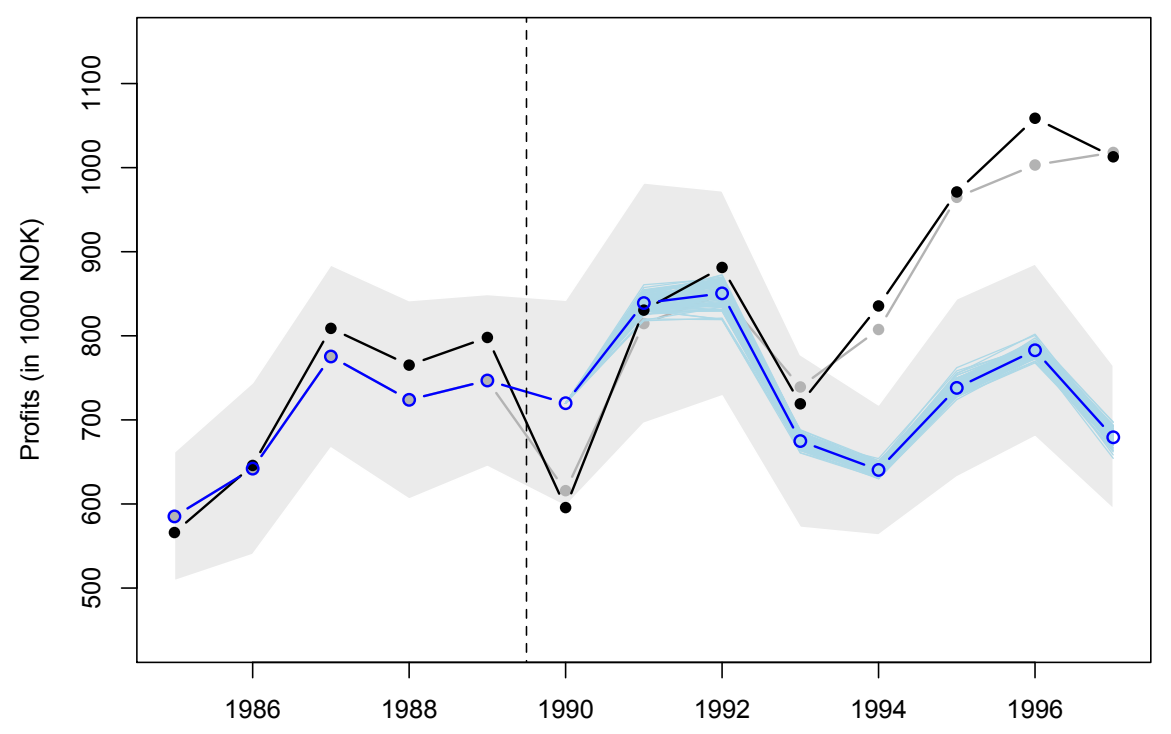

Figure 5: Average profits between 1985 and 1997. The black line with solid dots shows observed average profits. The blue line with open circles shows the average counterfactual profits in absence of the intervention. The grey area represents the $95 \%$ confidence band of this average. The light blue lines indicate the development of average profits when using a re-sampled biomass path as alternative counterfactual cod stock. Finally, the gray line with solid dots shows the predicted values of the profit function that controls for quotas and includes dummies and the actual observed cod stock.
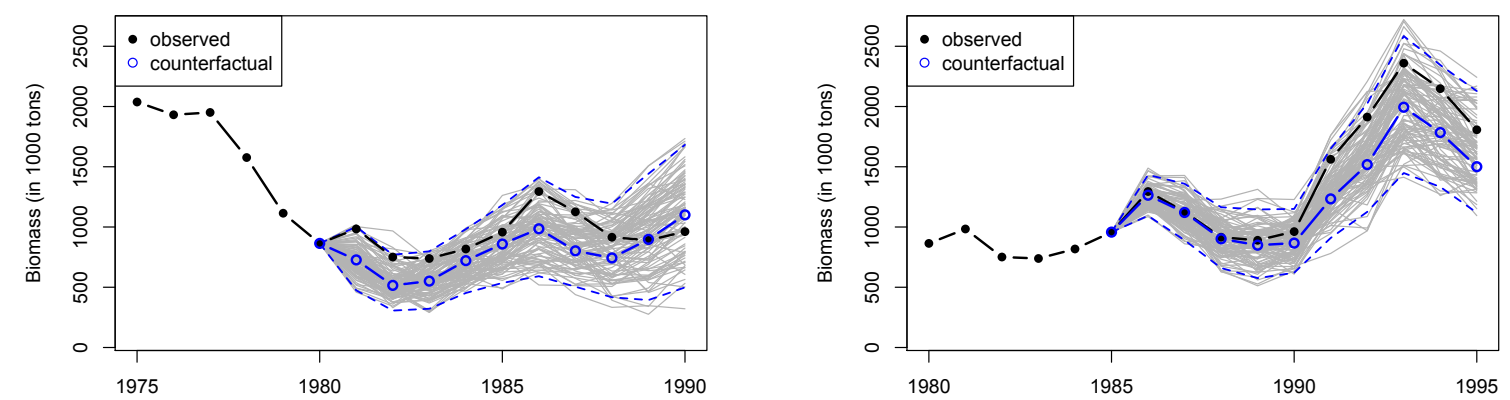

Figure 6: Placebo test: Applying the treatment to 1980 (left panel) and 1985 (right panel). Blue dashed lines give the $95 \%$ confidence interval. 

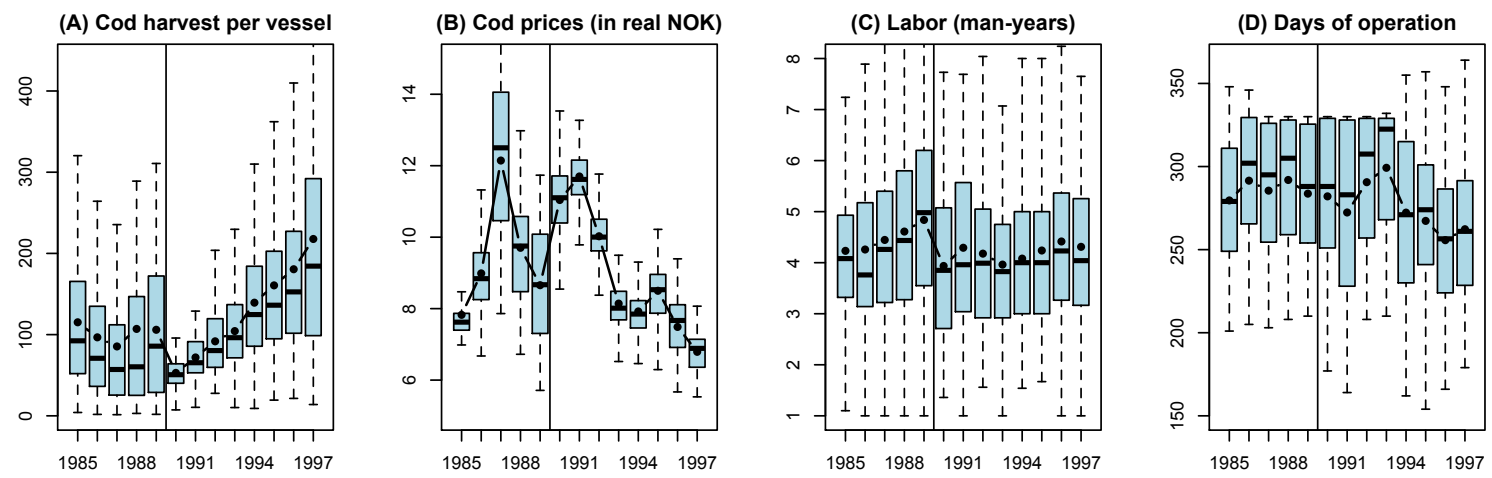

Figure 7: Boxplots of selected variables over time, full sample. The dots denote the mean and the thick line in the bars denote the median for a given year.
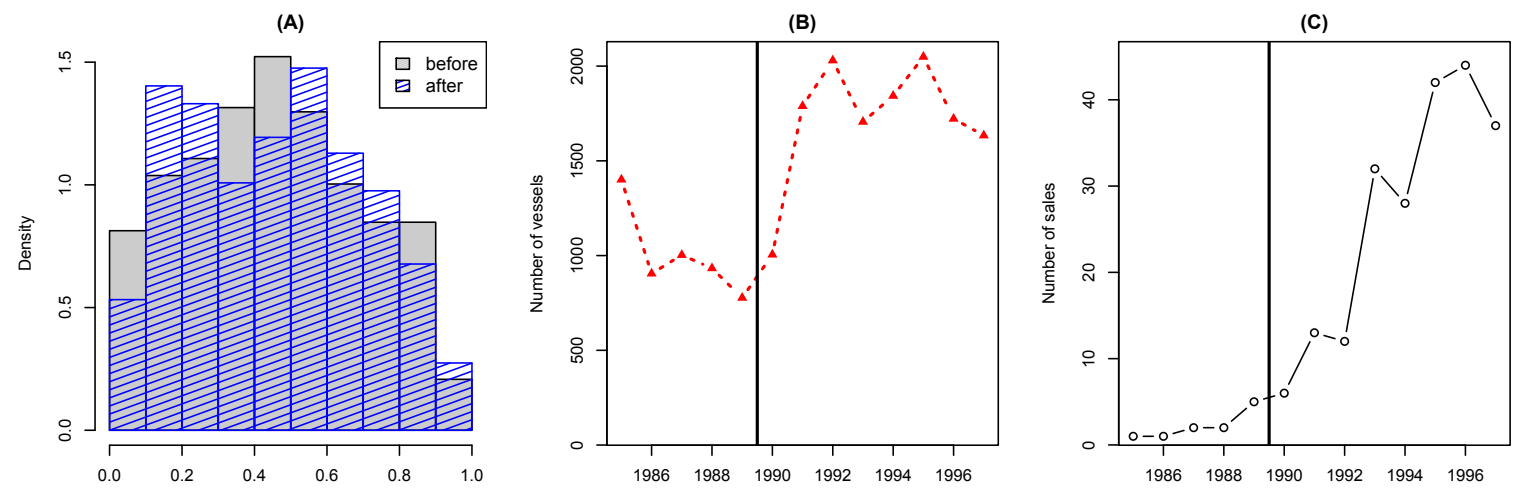

Figure 8: Additional aspects associated with higher profits. Panel (A): Histogram of share of cod in total harvest at the vessel level before and after 1989/90. Panel (B): Number of vessels that participate in the Lofoten fishery. Panel (C): Number of boat sales per year.

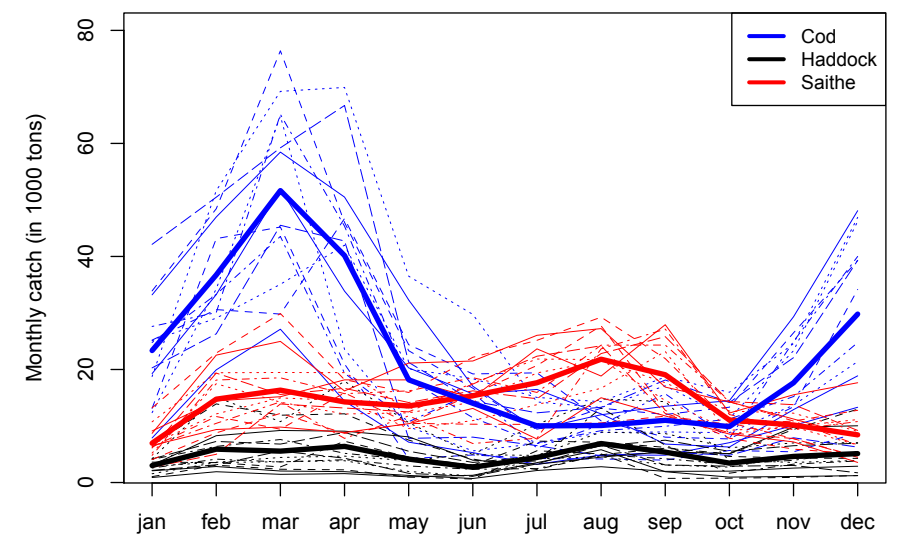

Figure A-1: Monthly Norwegian catch for the three most important species: cod (blue lines), haddock (black lines), and saithe (red lines). Each thin line represents catches over one year and the thick line shows the average from 1985-1997.; Data from Norwegian Official Statistics, Statistisk Sentralbyrå. 


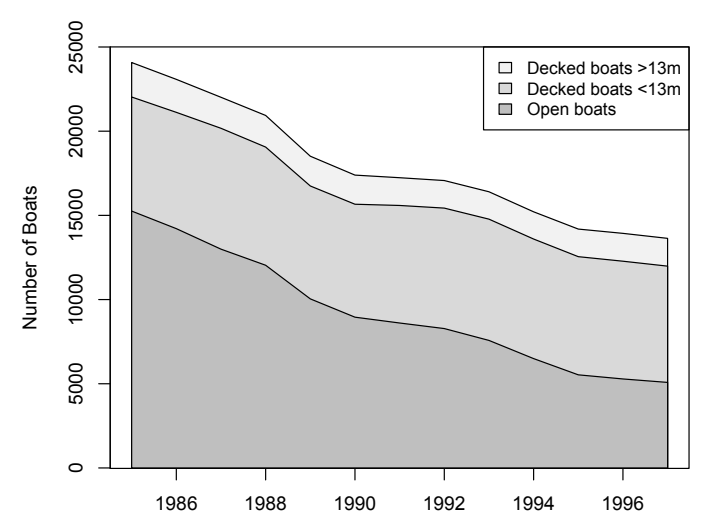

(A) All boats

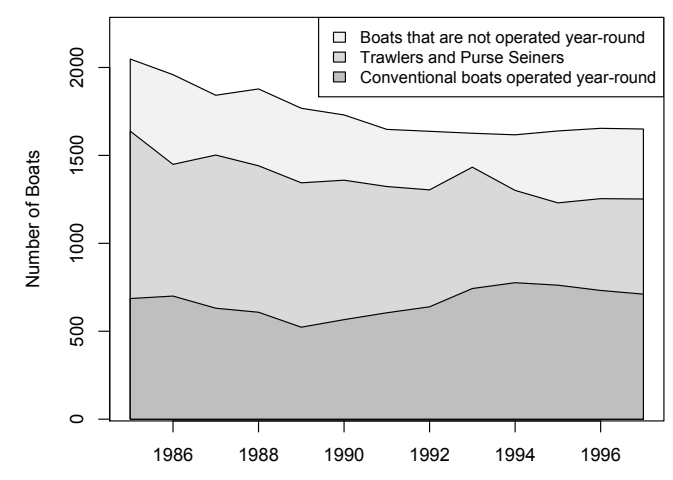

(B) Boats larger than $13 \mathrm{~m}$

Figure A-2: Registered fishing vessels; Data from Norwegian Official Statistics, 1985-97).

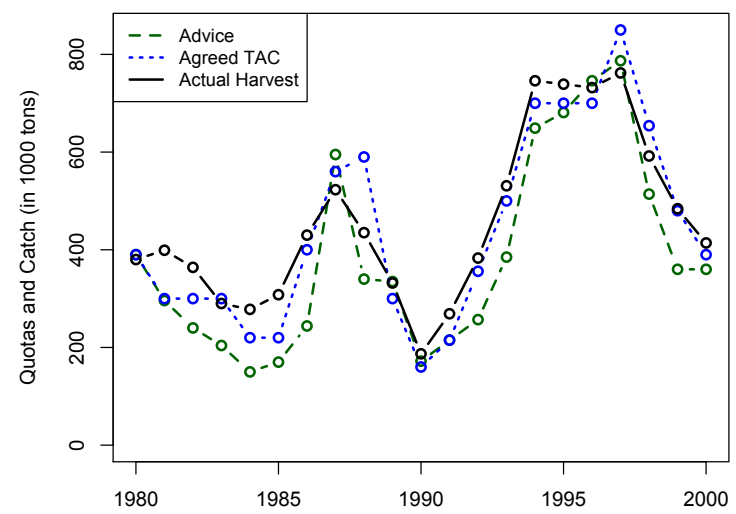

Figure A-3: Adviced and agreed total quotas and actual harvest 1980-2000.
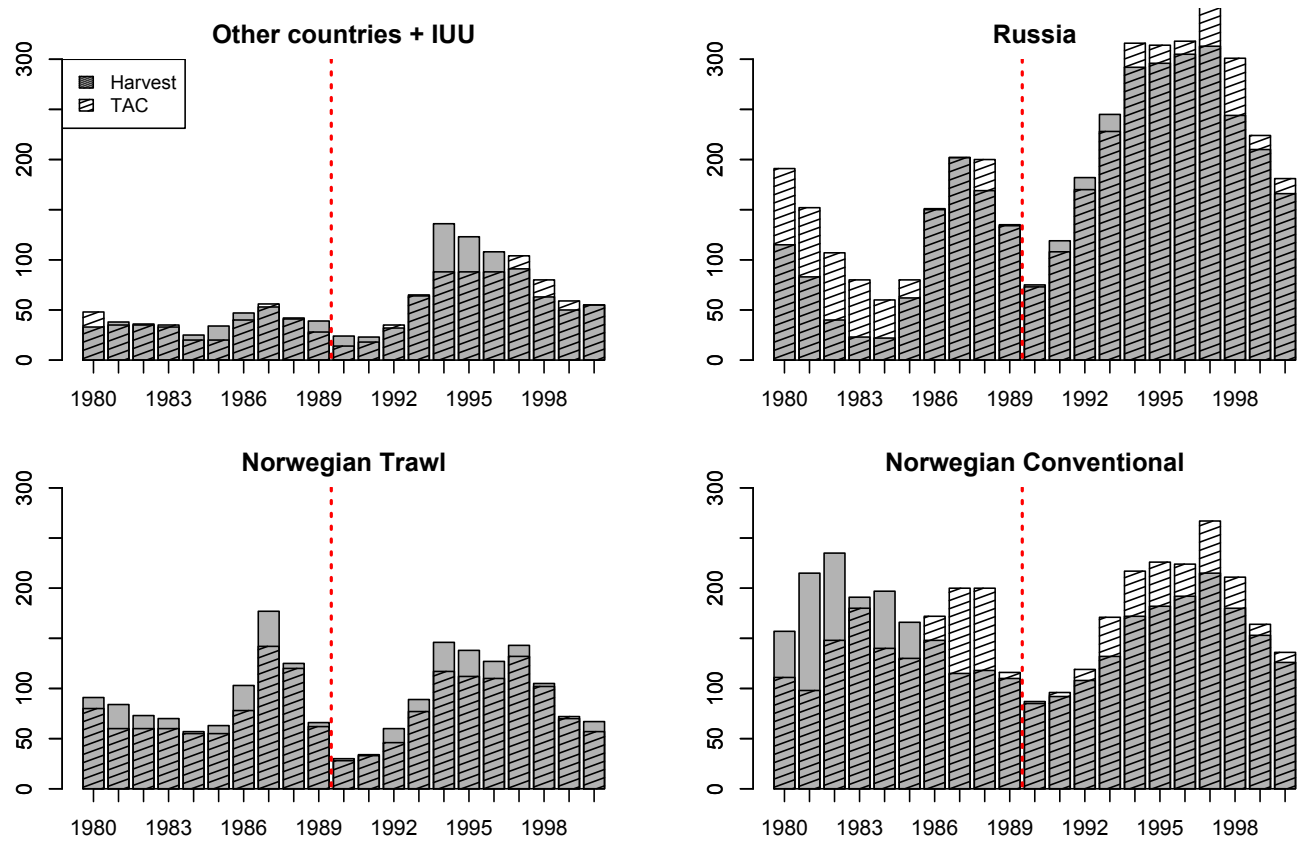

Figure A-4: Total quotas (hatched barplot) and actual harvest (solid grey barplot) 1980-2000. 

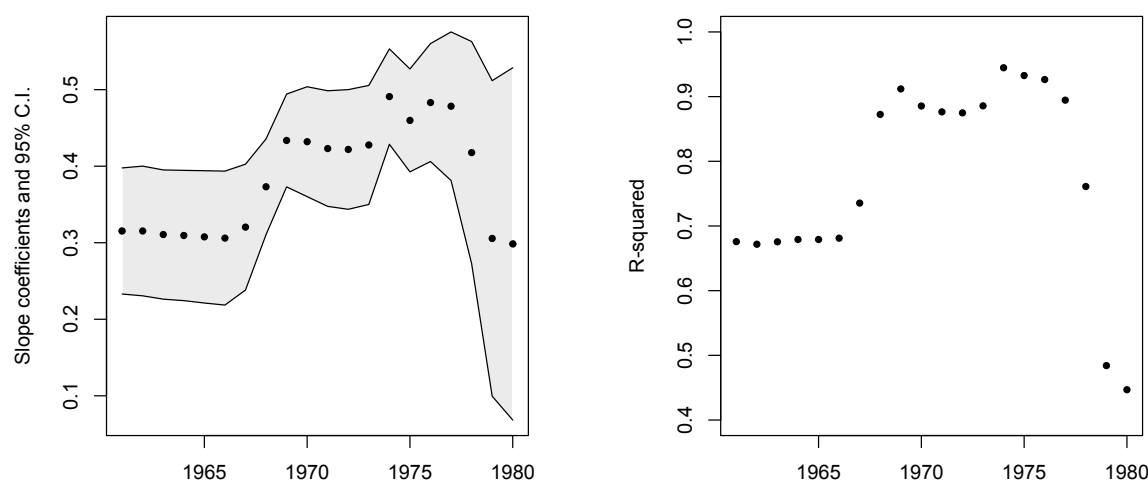

Figure A-5: Slope-coefficient (left panel) and $\mathrm{R}^{2}$ (right panel) for different starting years

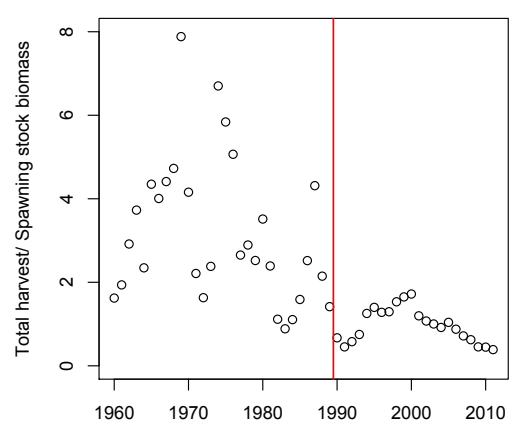

(A) Ratio of harvest to SSB

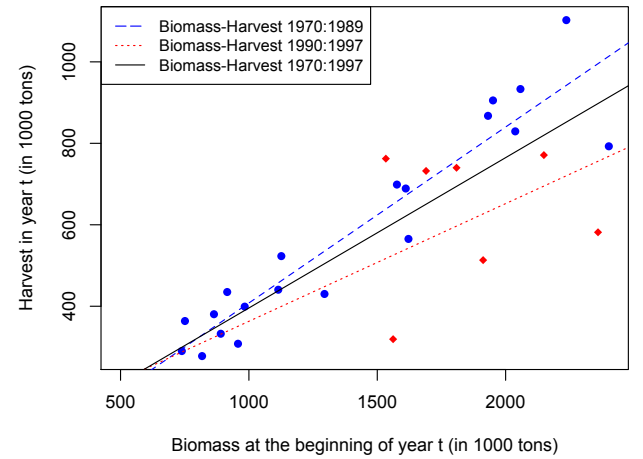

(A) Relationship biomass-harvest

Figure A-6: Evidence for a general change in NEA cod management
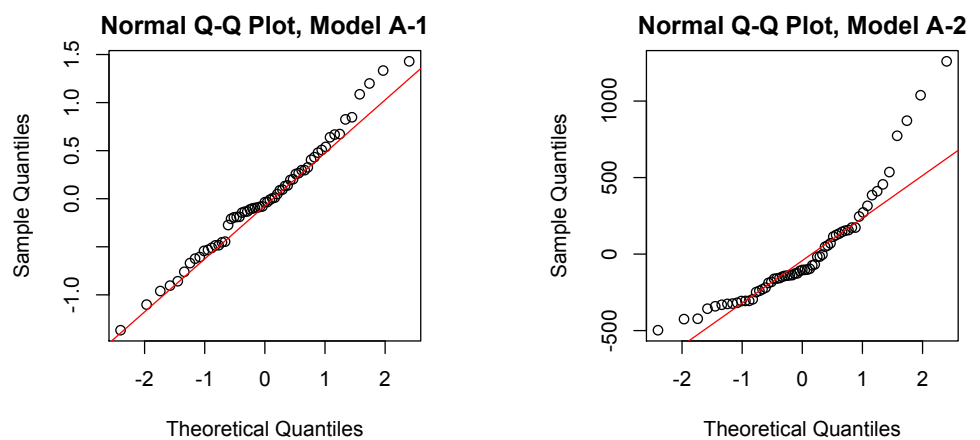

Figure A-7: Quantile-quantile plot comparing residuals from the recruitment estimation on data from 1946-2011 (Model A-1, left panel, and Model A-2, right panel) to standard normal distribution 


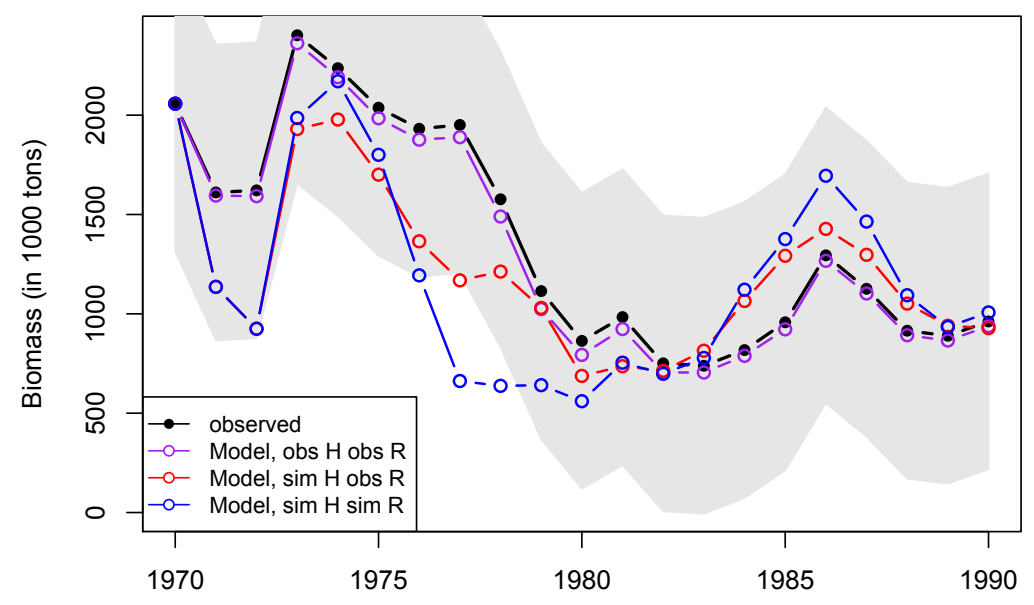

Figure A-8: Observed and counterfactual stock biomass values 1970-1990

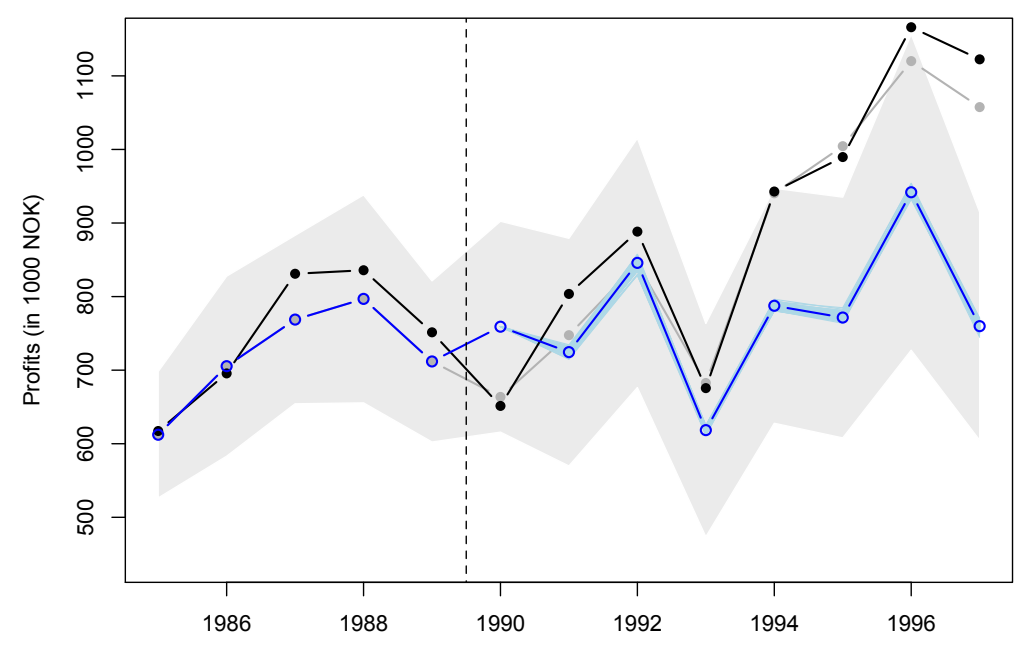

Figure A-9: Average profits of the restricted sample of boats-owner combinations that have been observed both before and after the policy change. The black line with solid dots shows observed average profits. The blue line with open circles shows the average counterfactual profits in absence of the intervention. The grey area represents the $95 \%$ confidence band of this average. The light blue lines indicate the development of average profits when using a re-sampled biomass path as alternative counterfactual cod stock. Finally, the gray line with solid dots shows the predicted values of the profit function that controls for quotas and includes dummies and the actual observed cod stock. 